\title{
Supplement
}

Supplement of:

Modeling the influence of snowcover temperature and water content on wet snow avalanche runout

Authors: C. Vera Valero ${ }^{1}$, N. Wever ${ }^{2}$, M. Christen ${ }^{1}$, P. Bartelt ${ }^{1}$

${ }^{1}$ WSL Institute for Snow and Avalanche Research SLF, Davos Dorf, Switzerland.

2 École Polytechnique Fédérale de Lausanne (EPFL), School of Architecture, Civil and Environmental Engineering, Lausanne, Switzerland. 


\section{Supplement A}

The following pages show the avalanche calculations performed with the thermomechanical model RAMMS and the guideline-VS model for the 12 case studies. In each figure, the measured release (orange polygon) and deposits (violet polygon) areas are shown. 


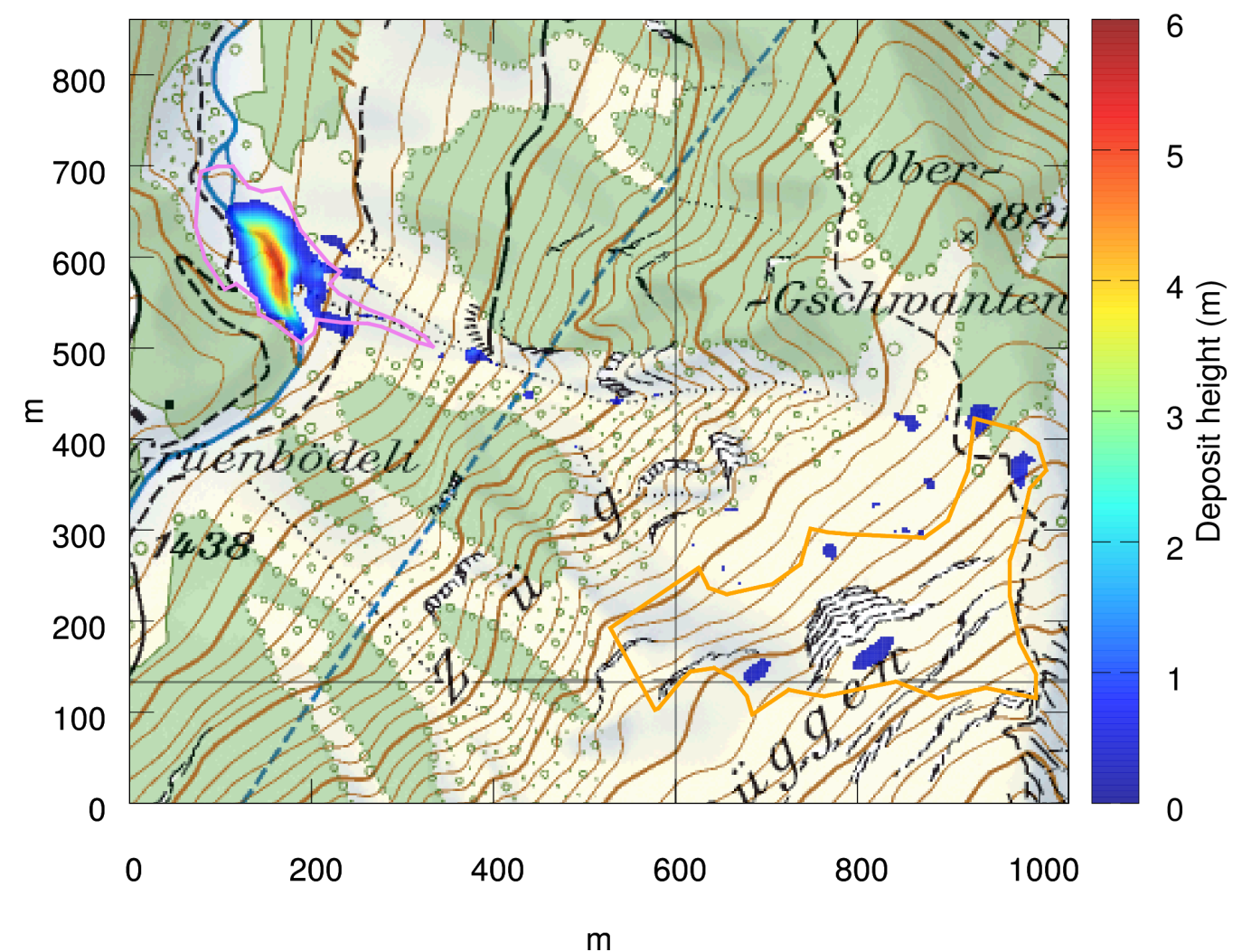

(a) Thermomechanical model RAMMS

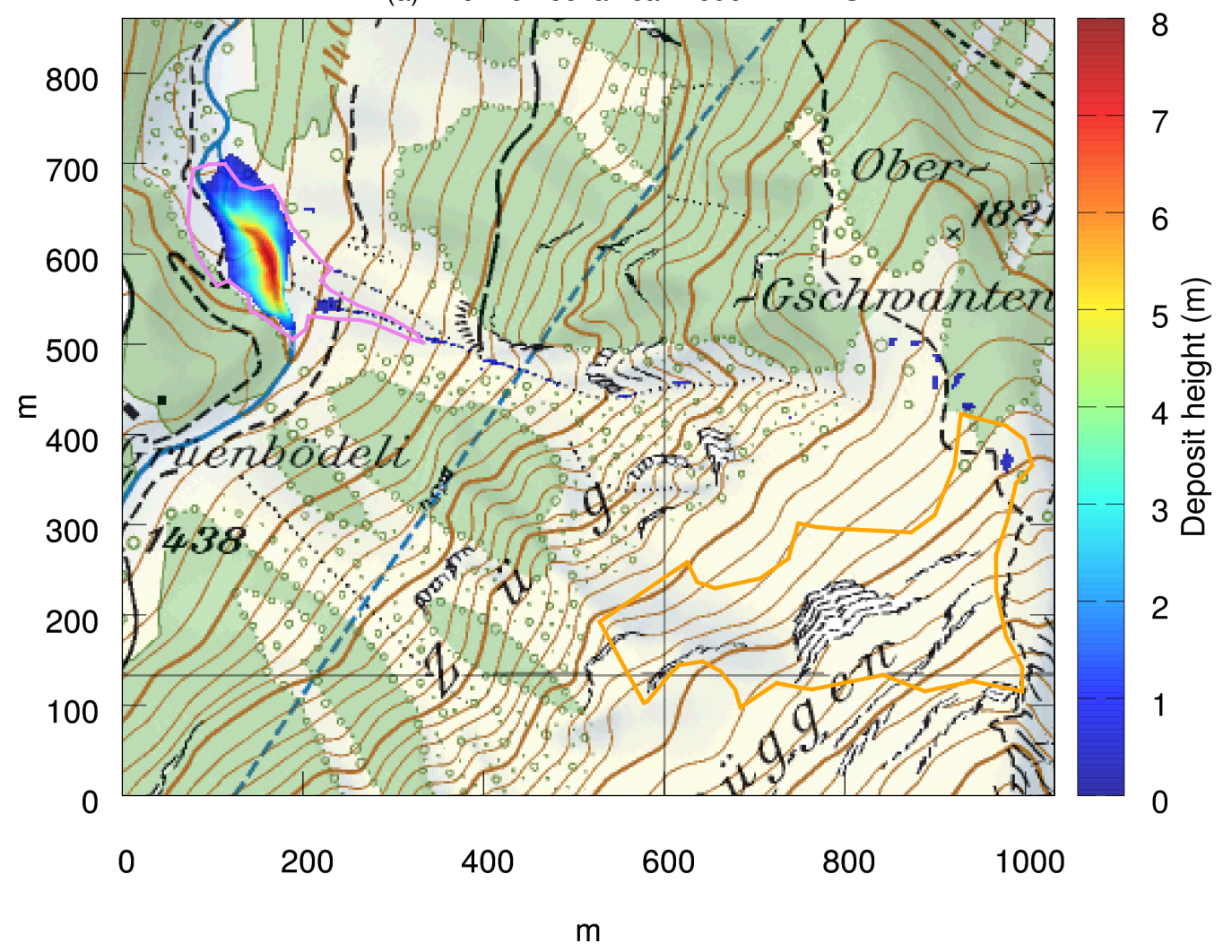

(b) Guideline-VS model

Figure S1: Gruenbodeli Davos 


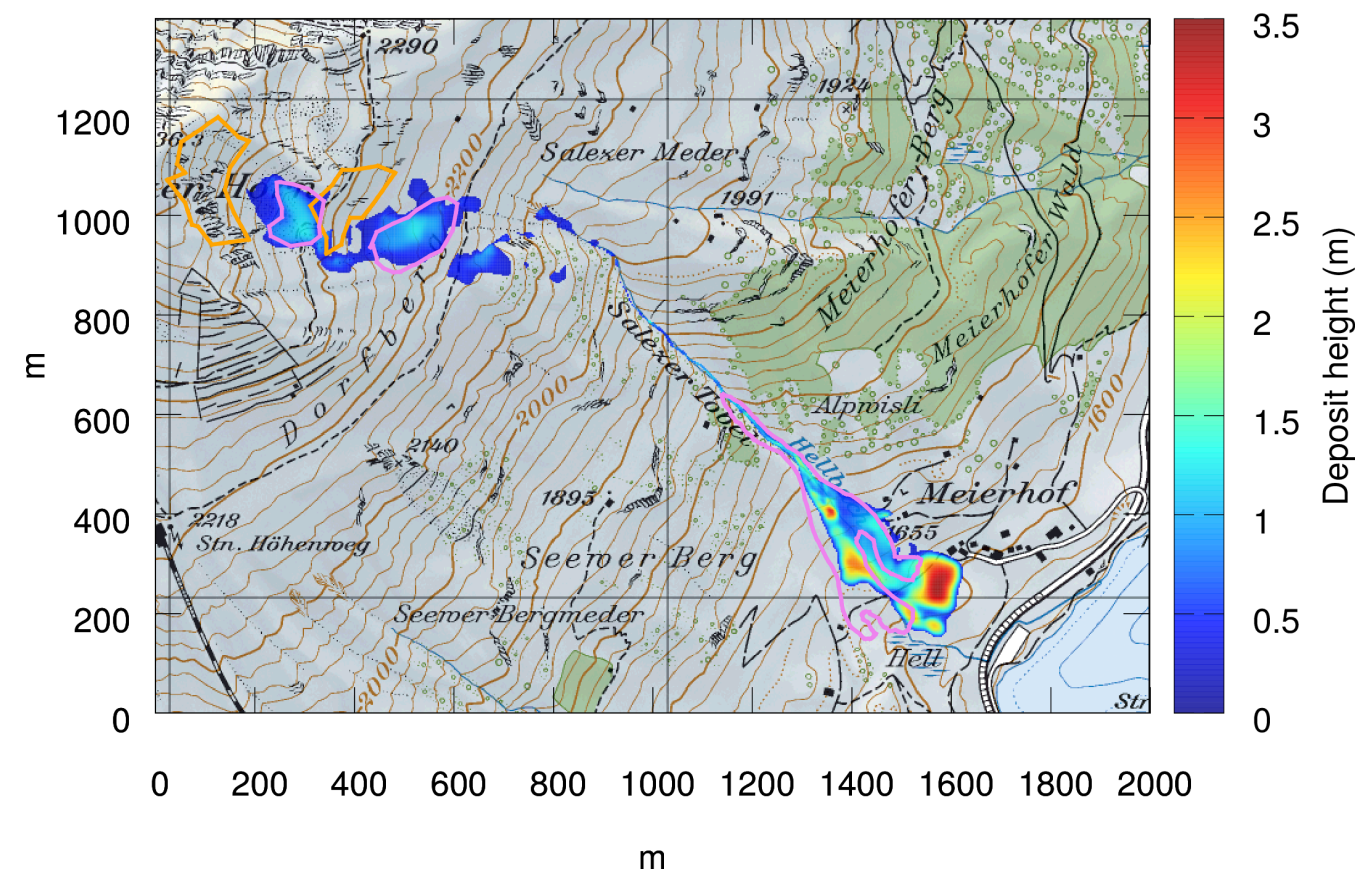

(a) Thermomechanical model RAMMS

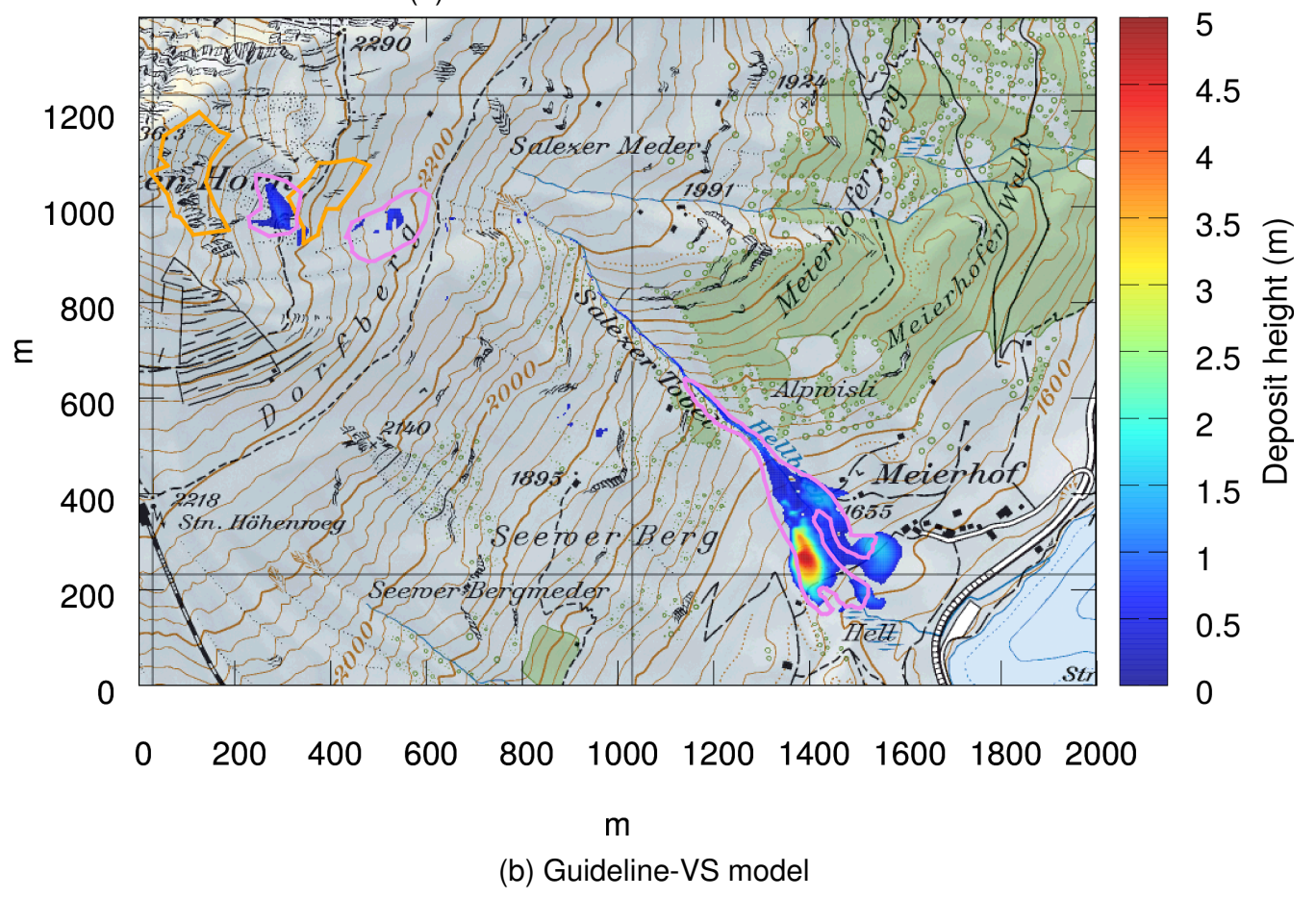

Figure S2: Salezer Davos 


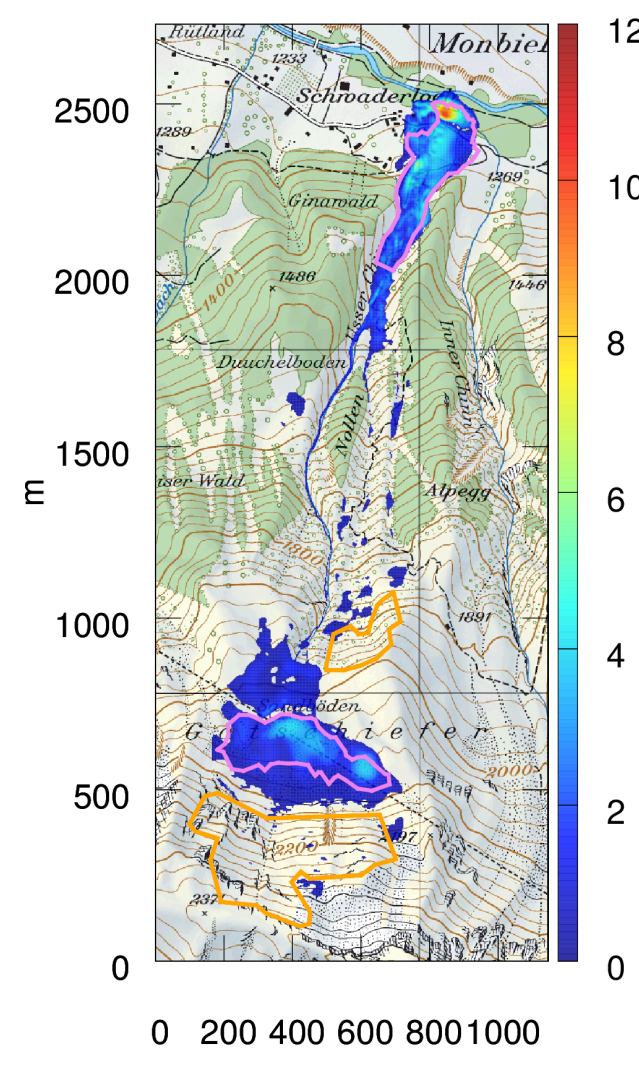

m

(a) Thermomechanical model RAMMS

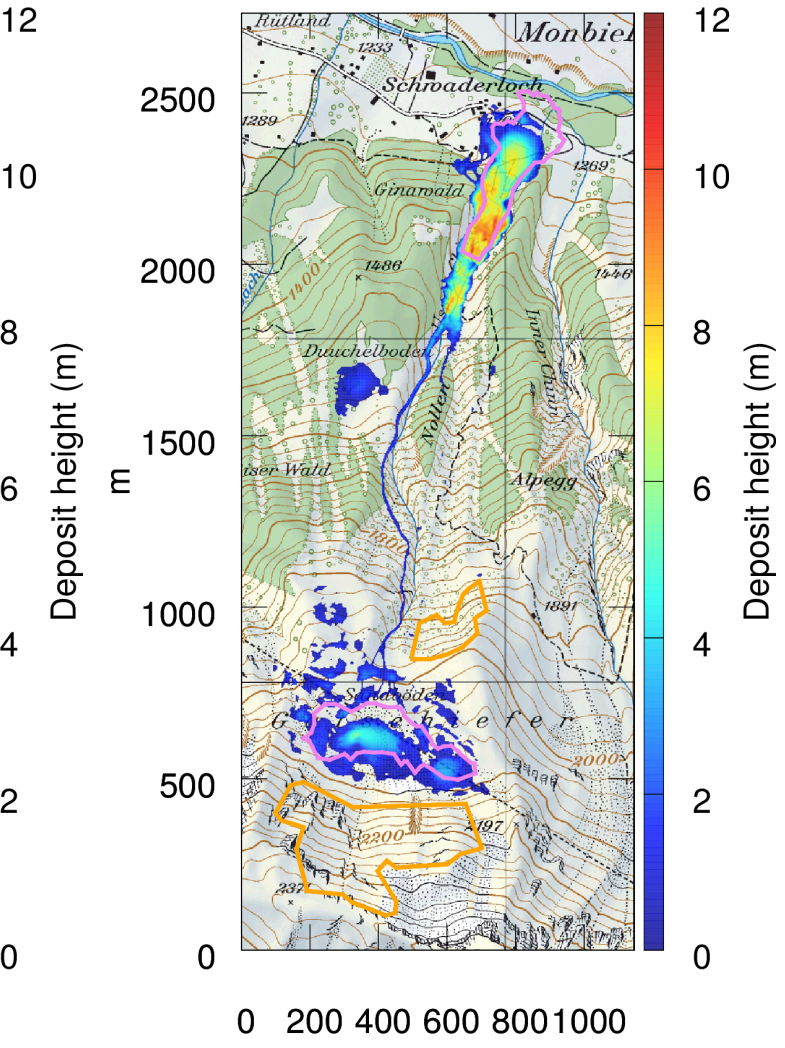

$\mathrm{m}$

(b) Guideline-VS model

Figure S3: Gatschiefer Davos 


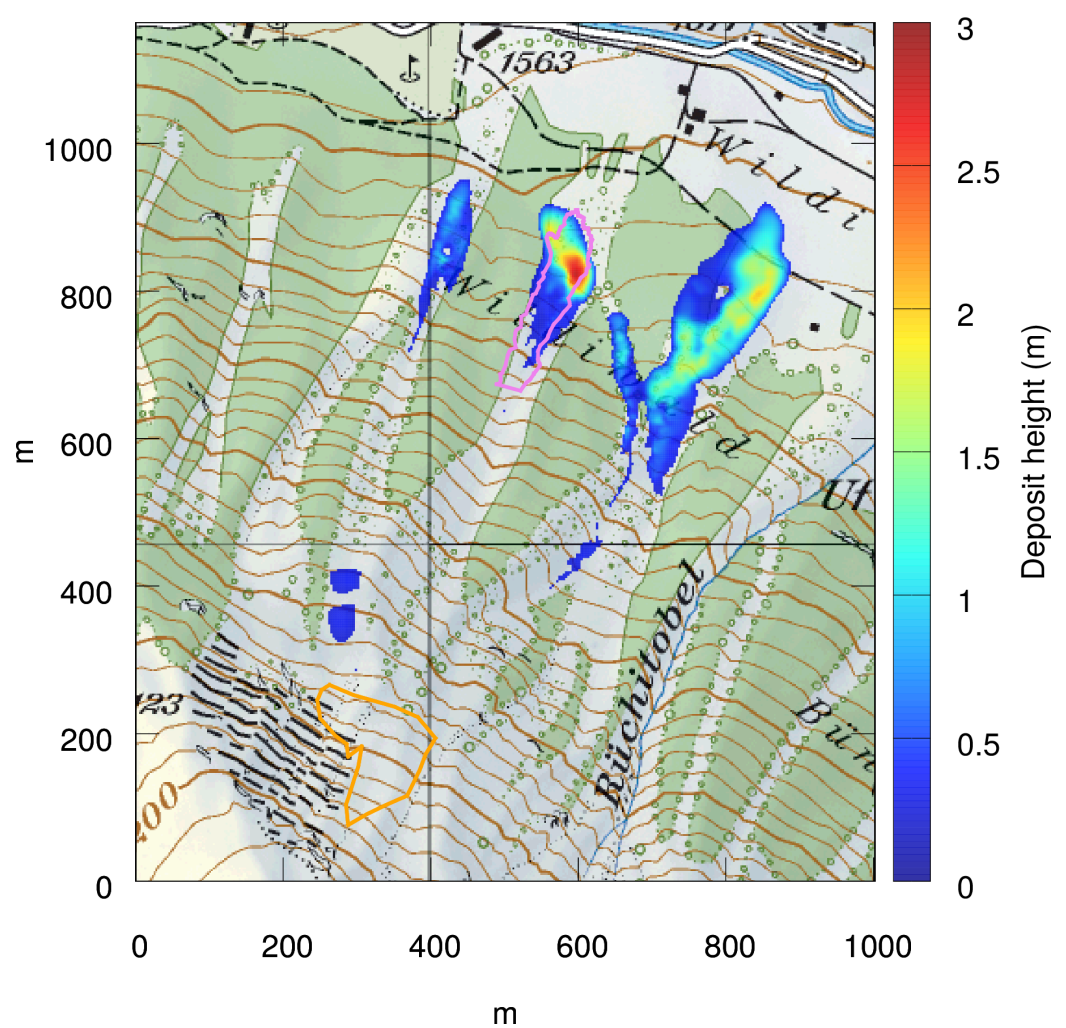

(a) Thermomechanical model RAMMS

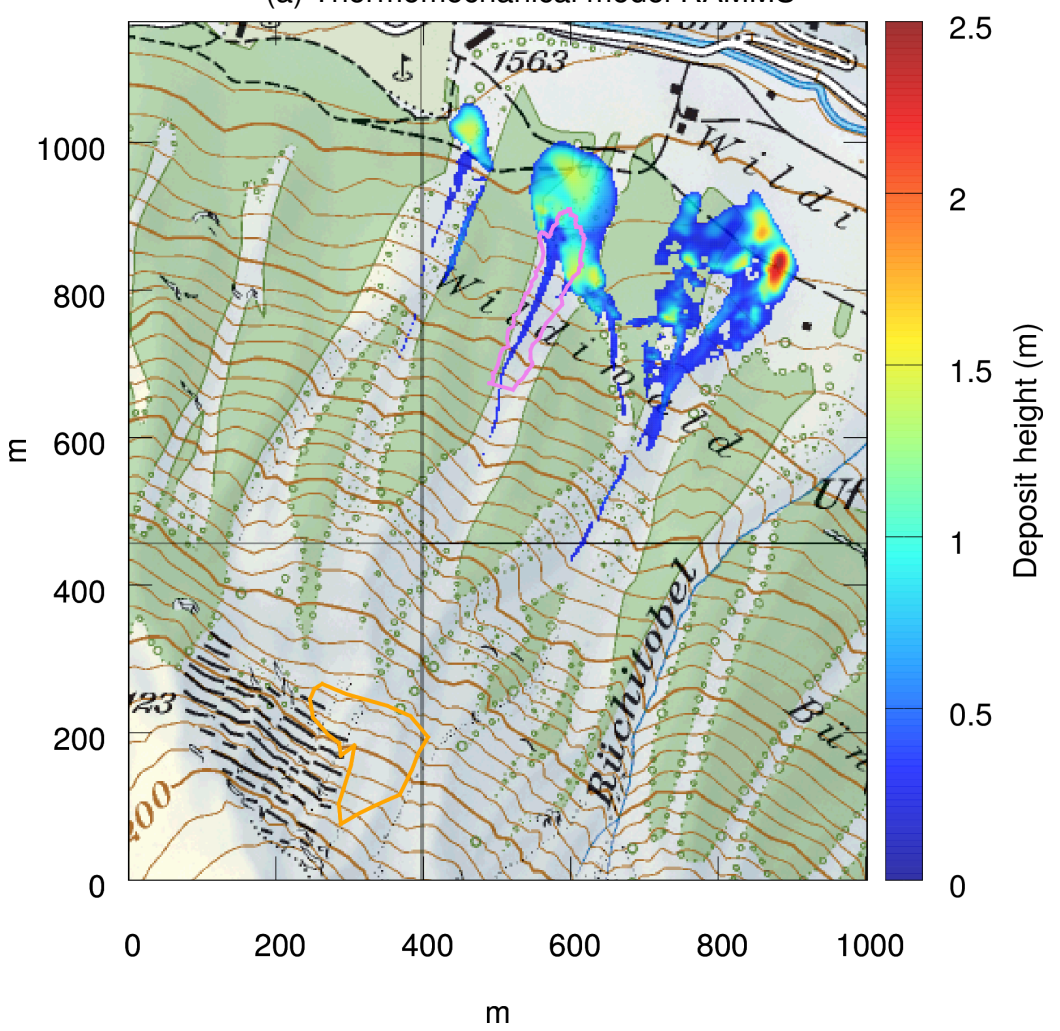

(b) Guideline-VS model

Figure S4: Braemabuhl 2013 Davos 


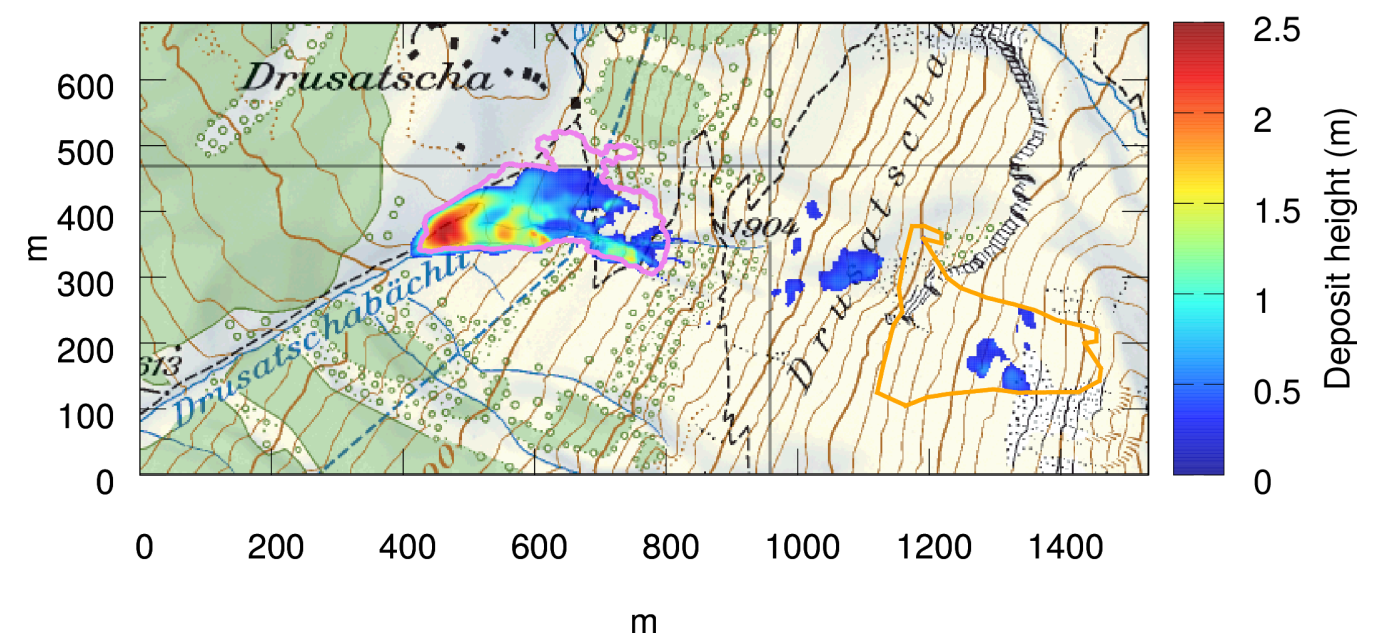

(a) Thermomechanical model RAMMS

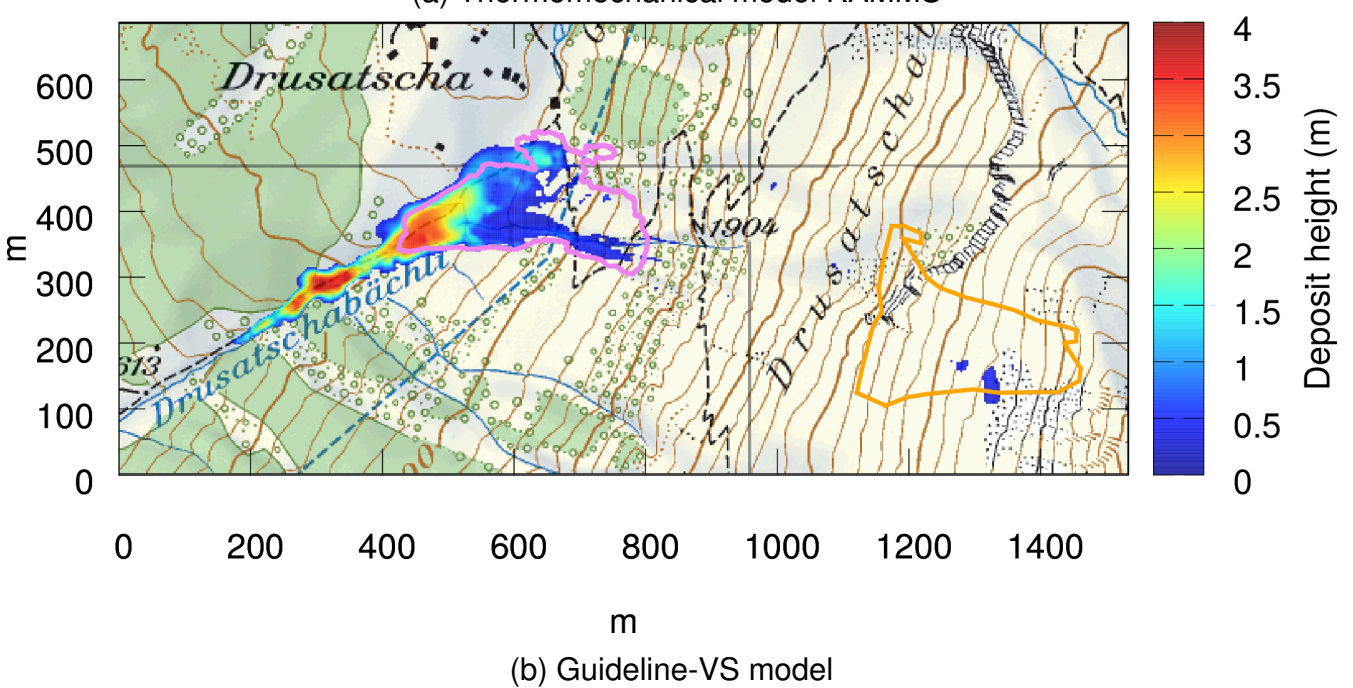

Figure S5: Drusatscha Davos 


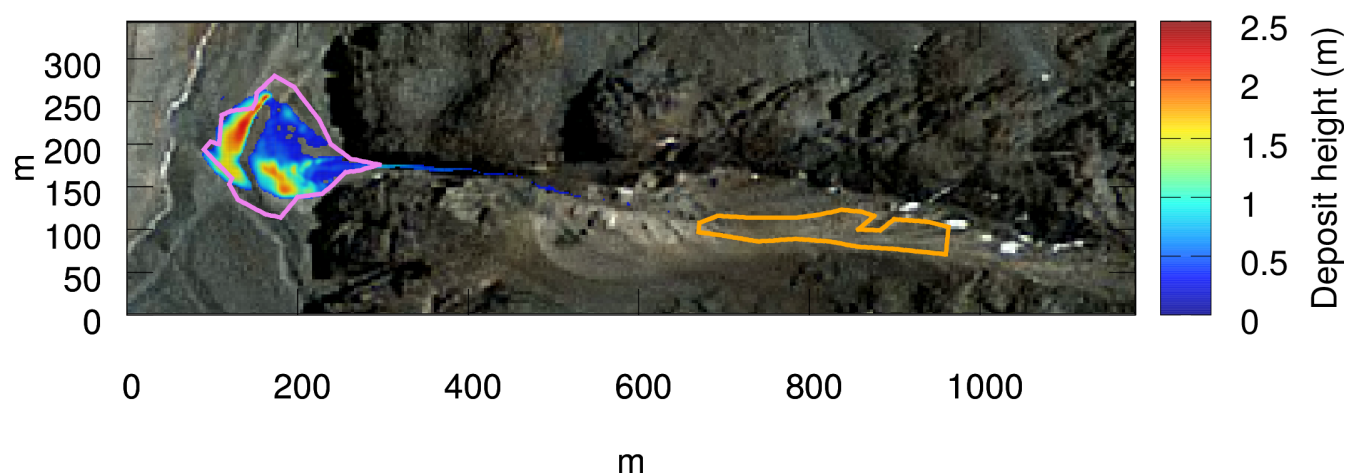

(a) Thermomechanical model RAMMS

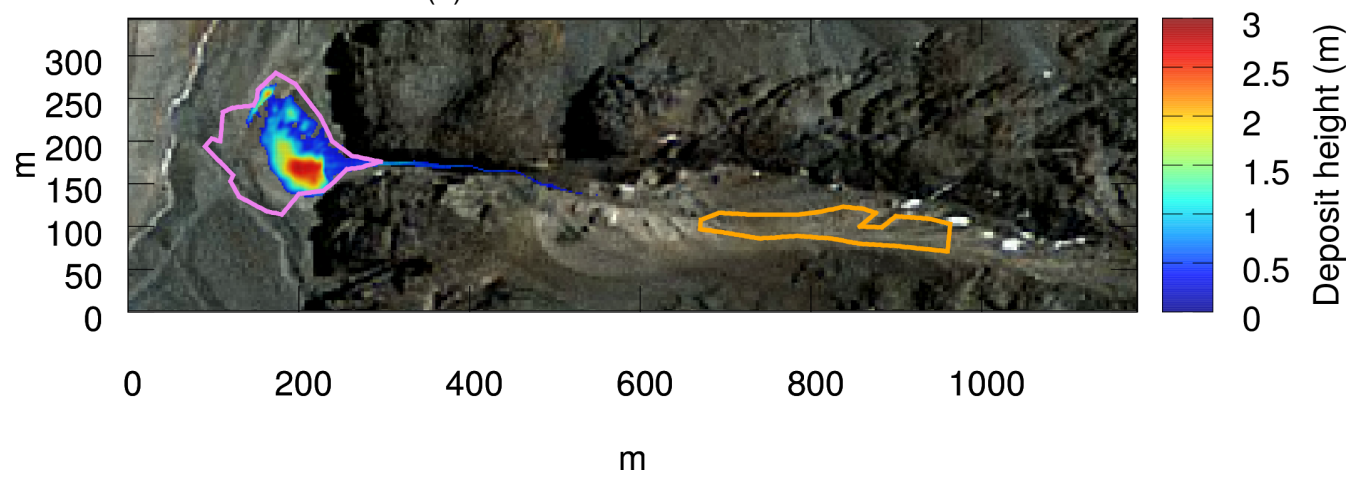

(b) Guideline-VS model

Figure S6: Codelco Andina MO-4 


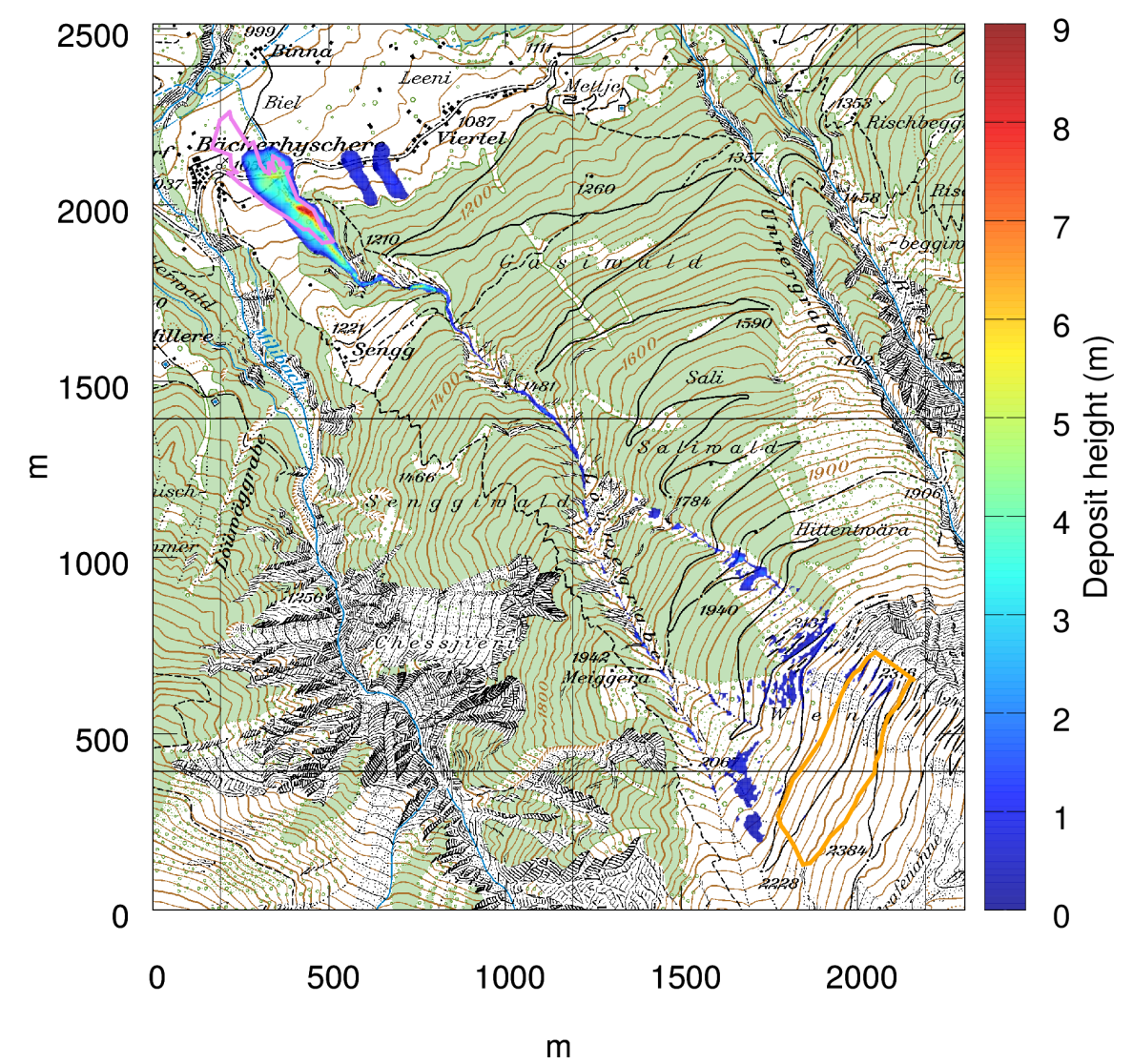

(a) Thermomechanical model RAMMS

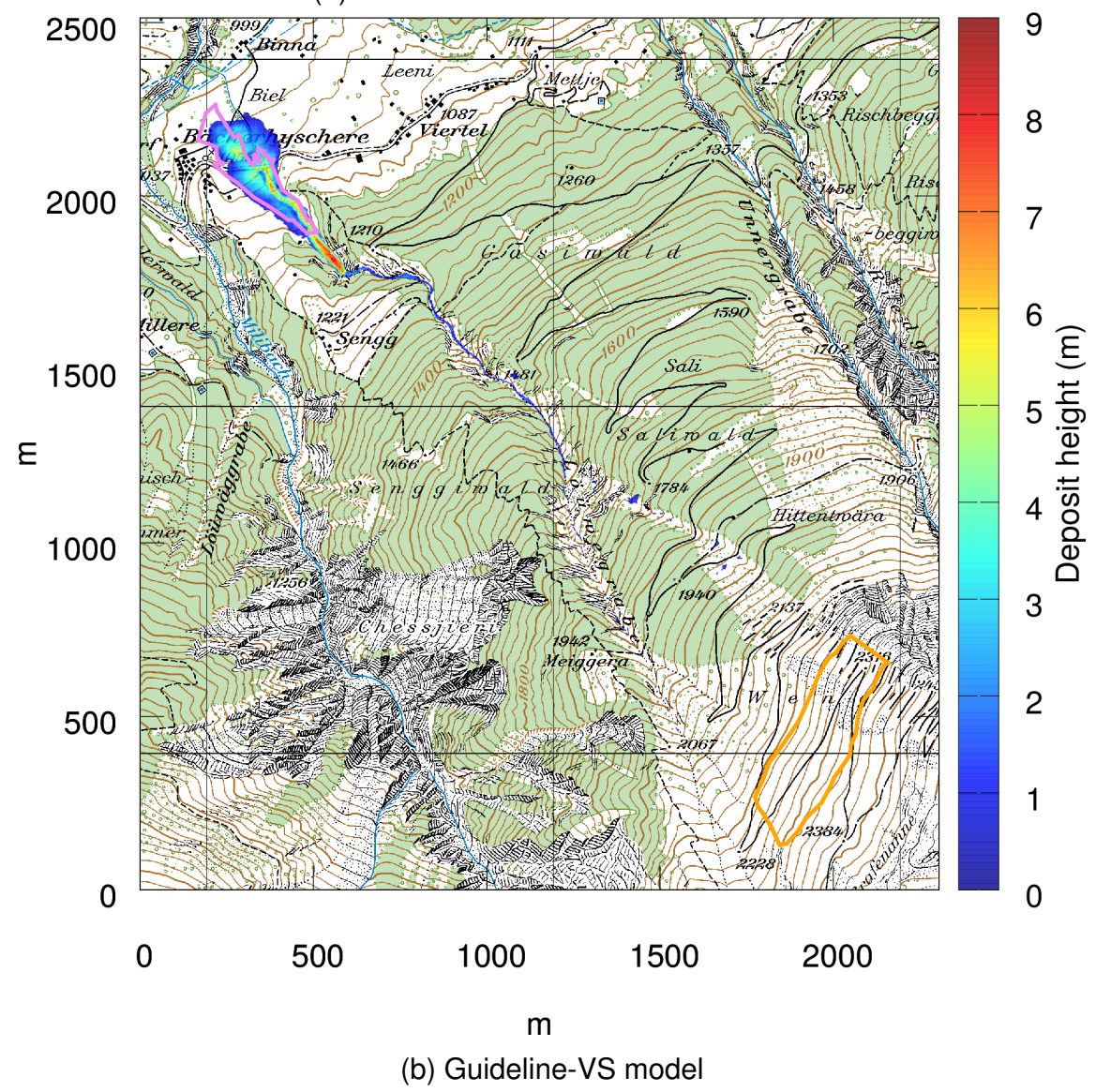

Figure S7: Grengiols 


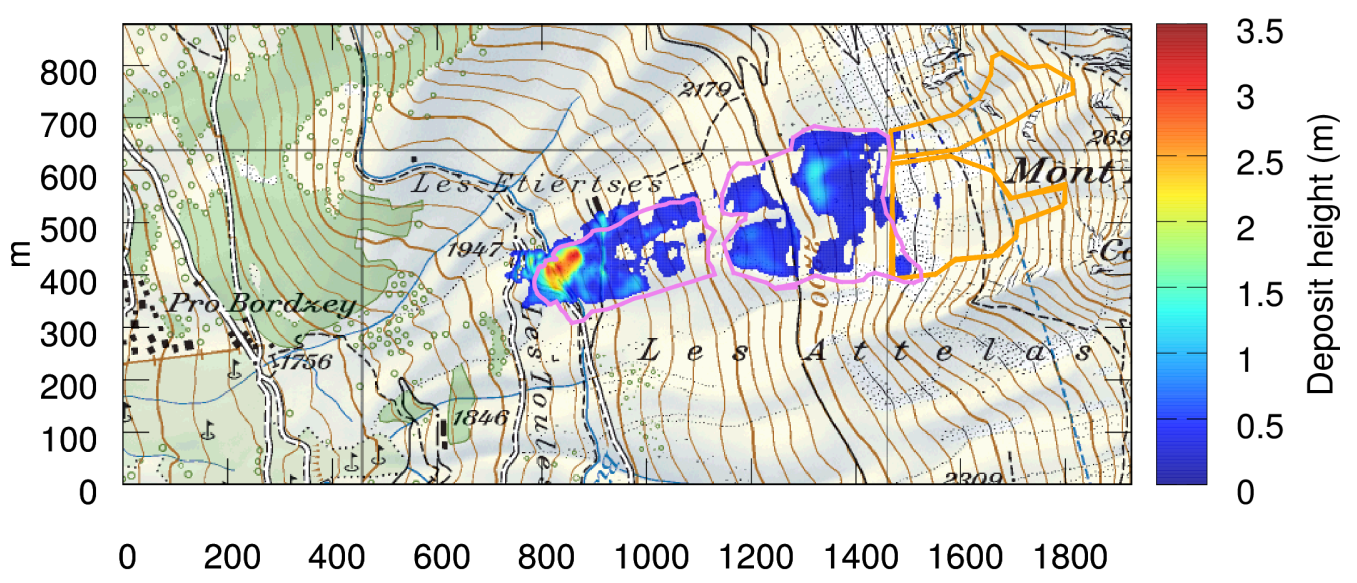

$\mathrm{m}$

(a) Thermomechanical model RAMMS

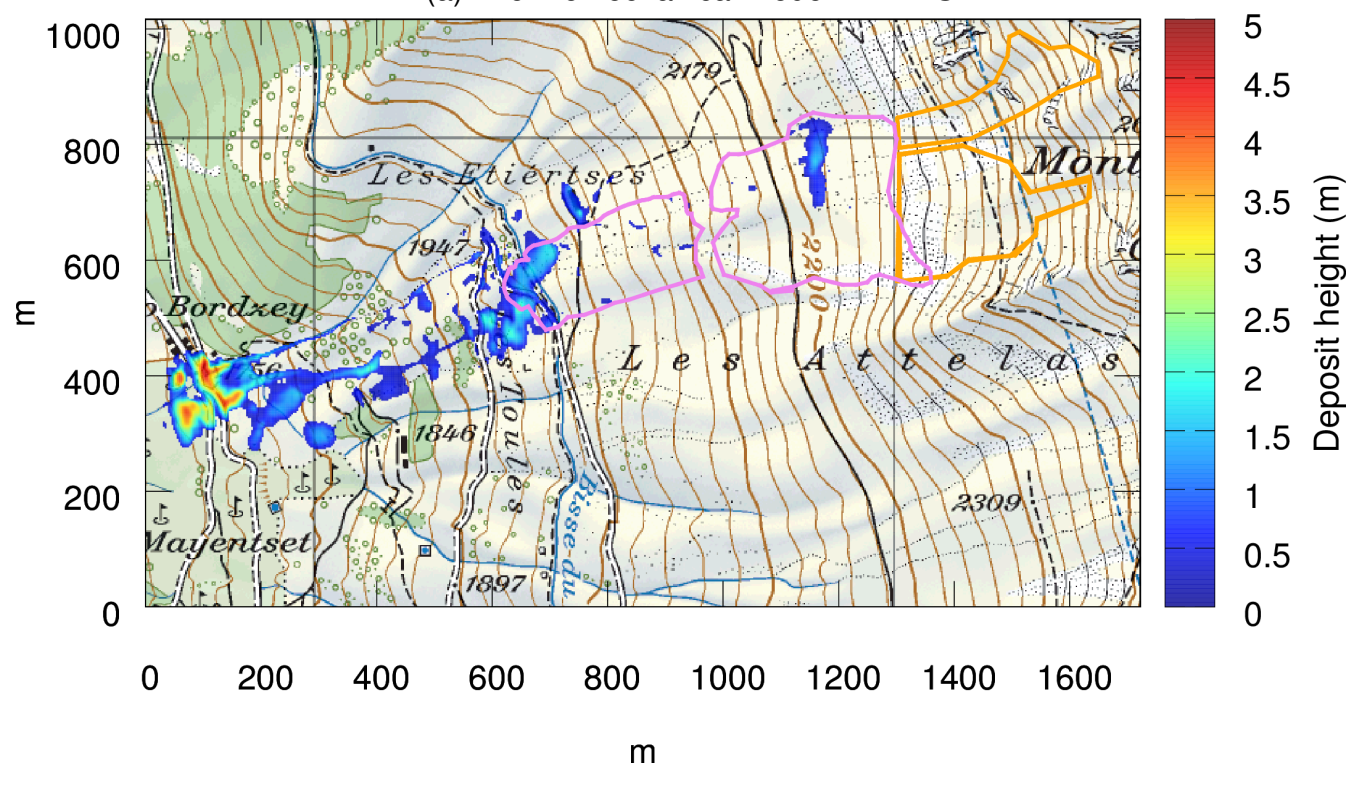

(b) Guideline-VS model

Figure S8: Mont Rogneux Verbier 


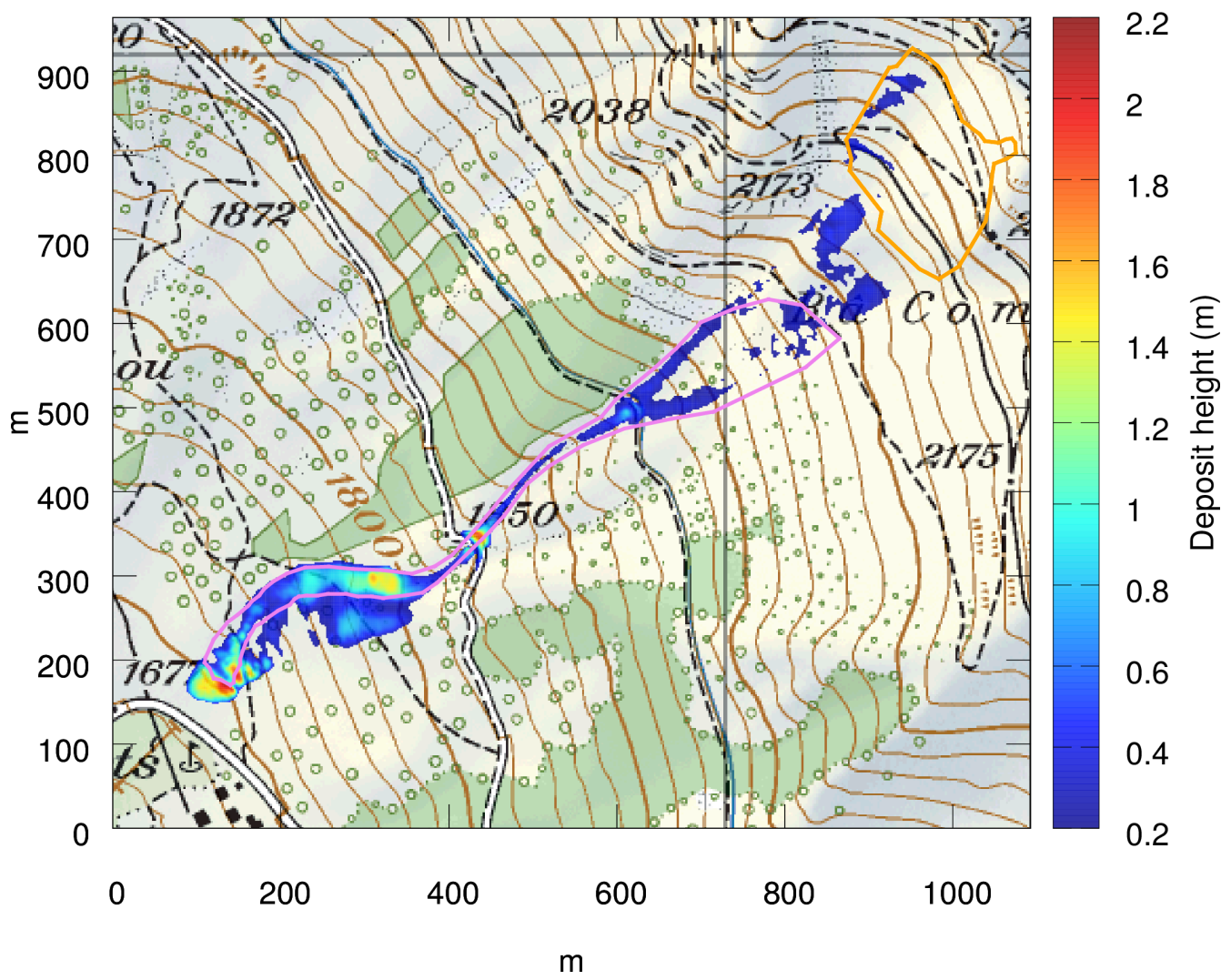

(a) Thermomechanical model RAMMS

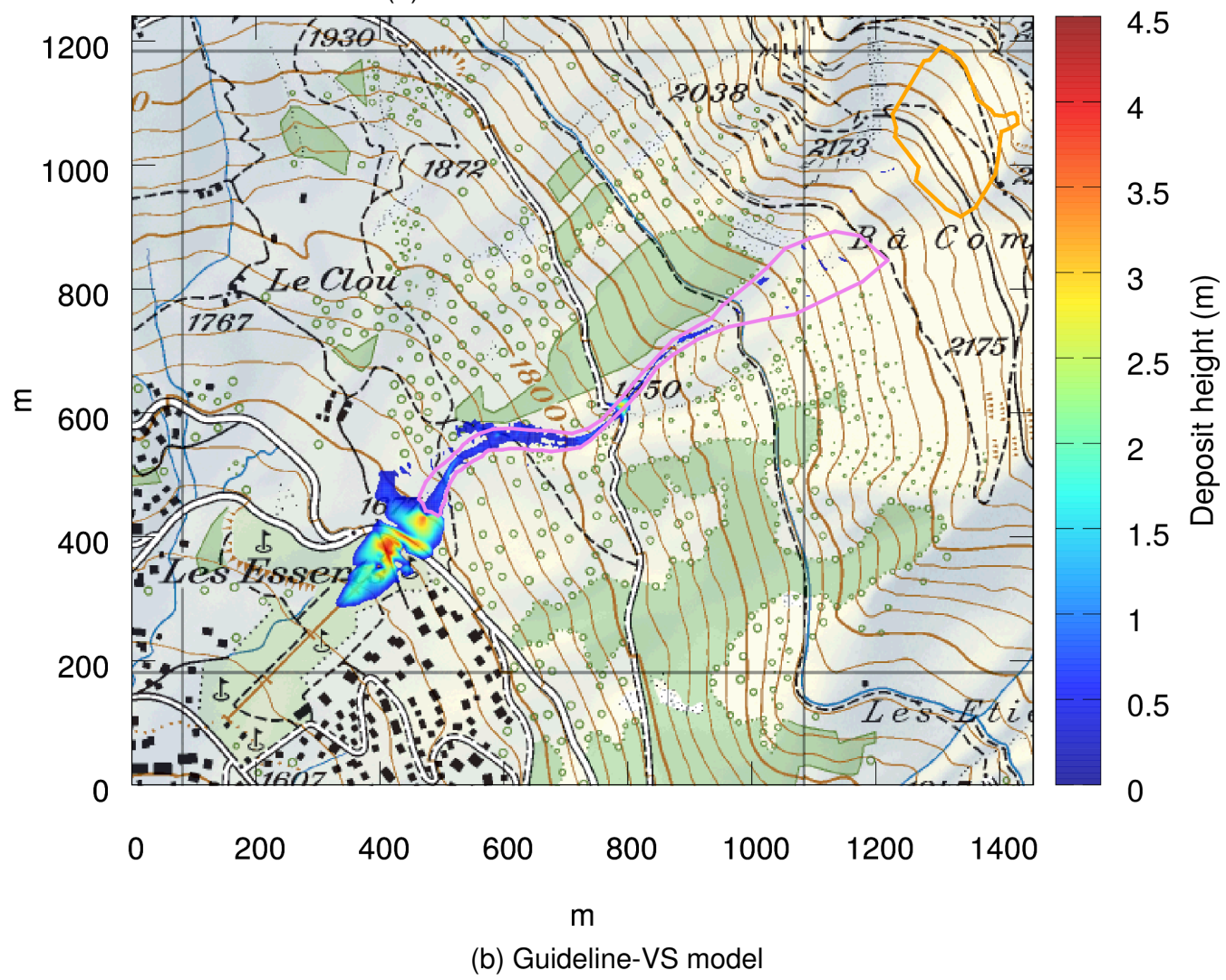

Figure S9: Ba Combe Verbier 


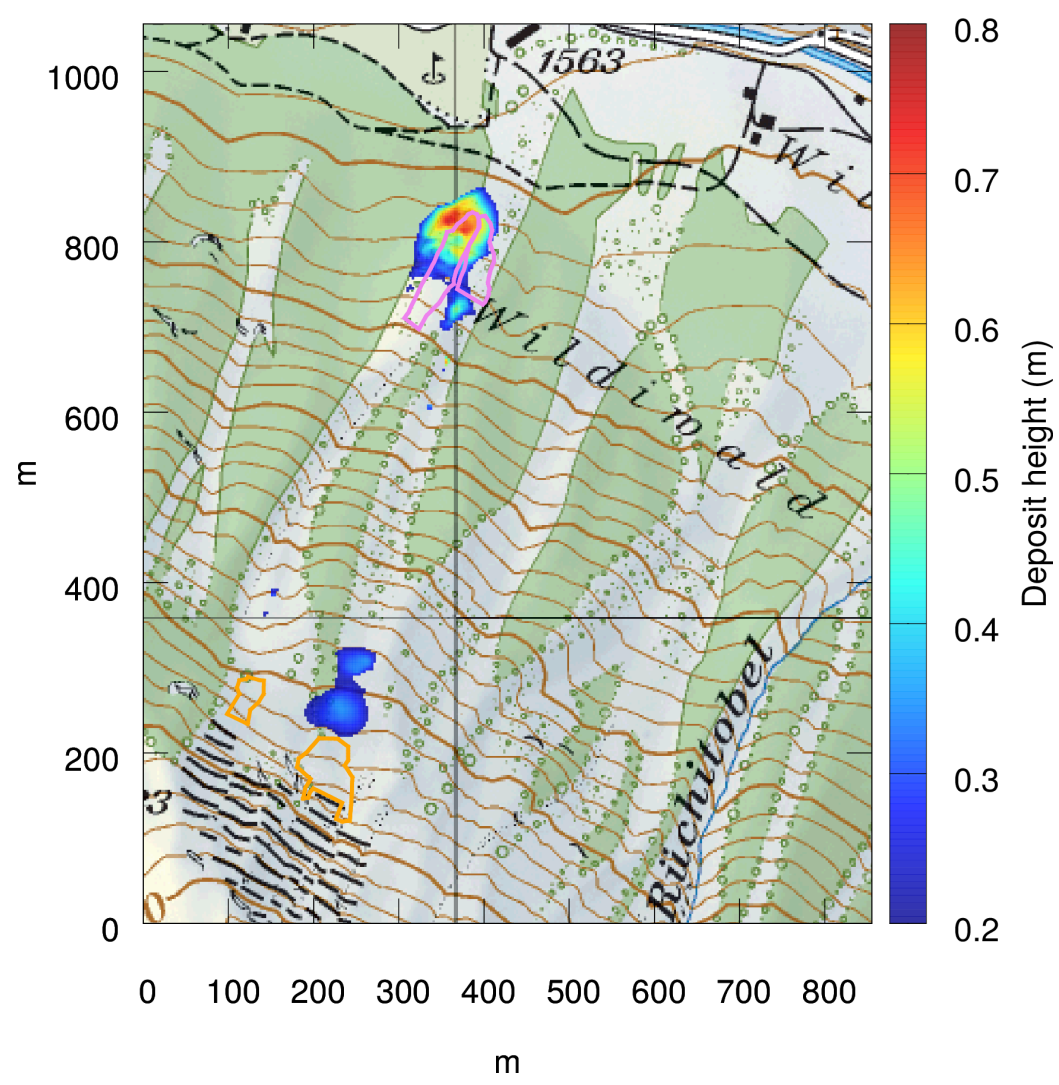

(a) Thermomechanical model RAMMS

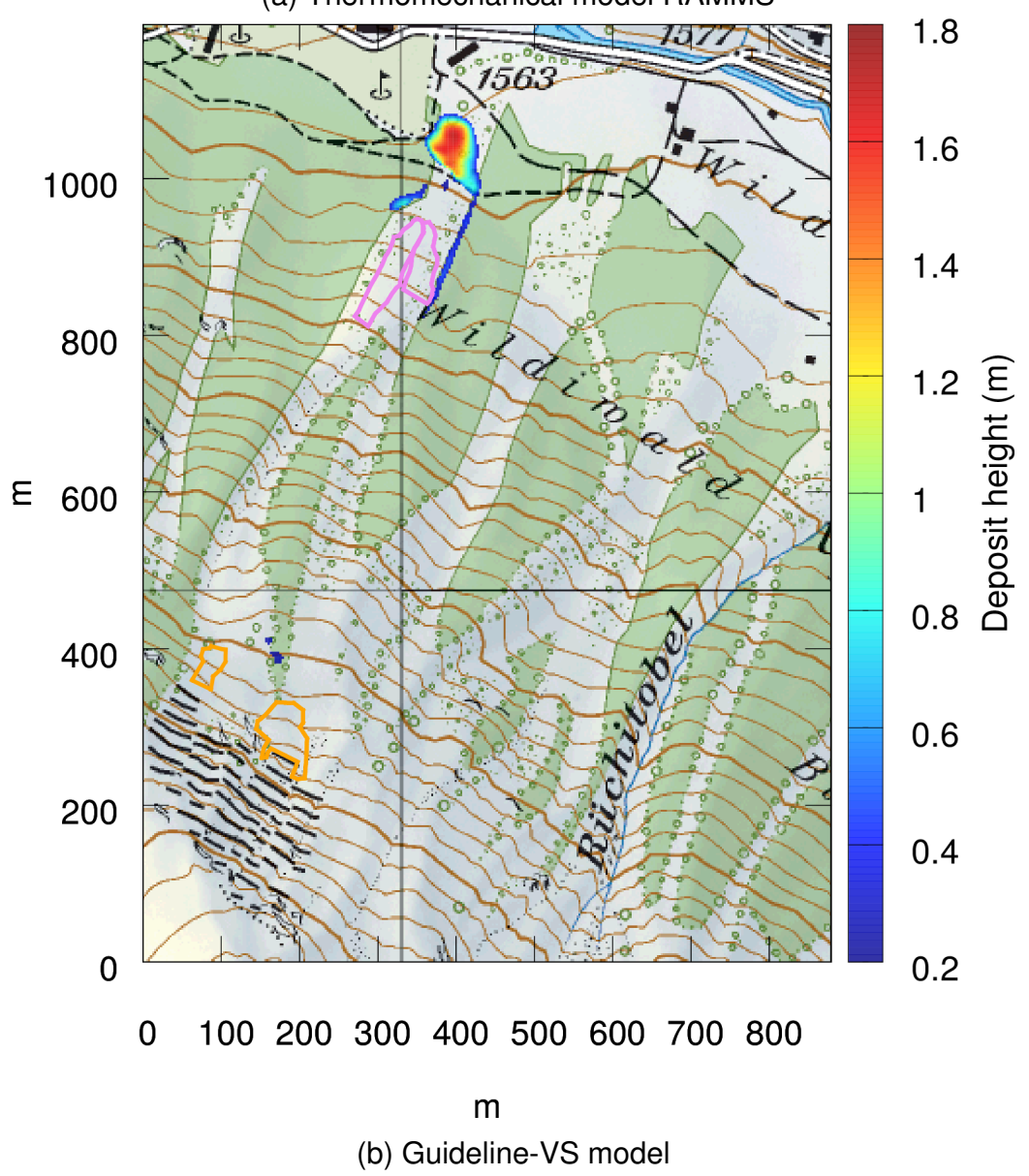

Figure S10: Braemabuhl Verbauung Davos 


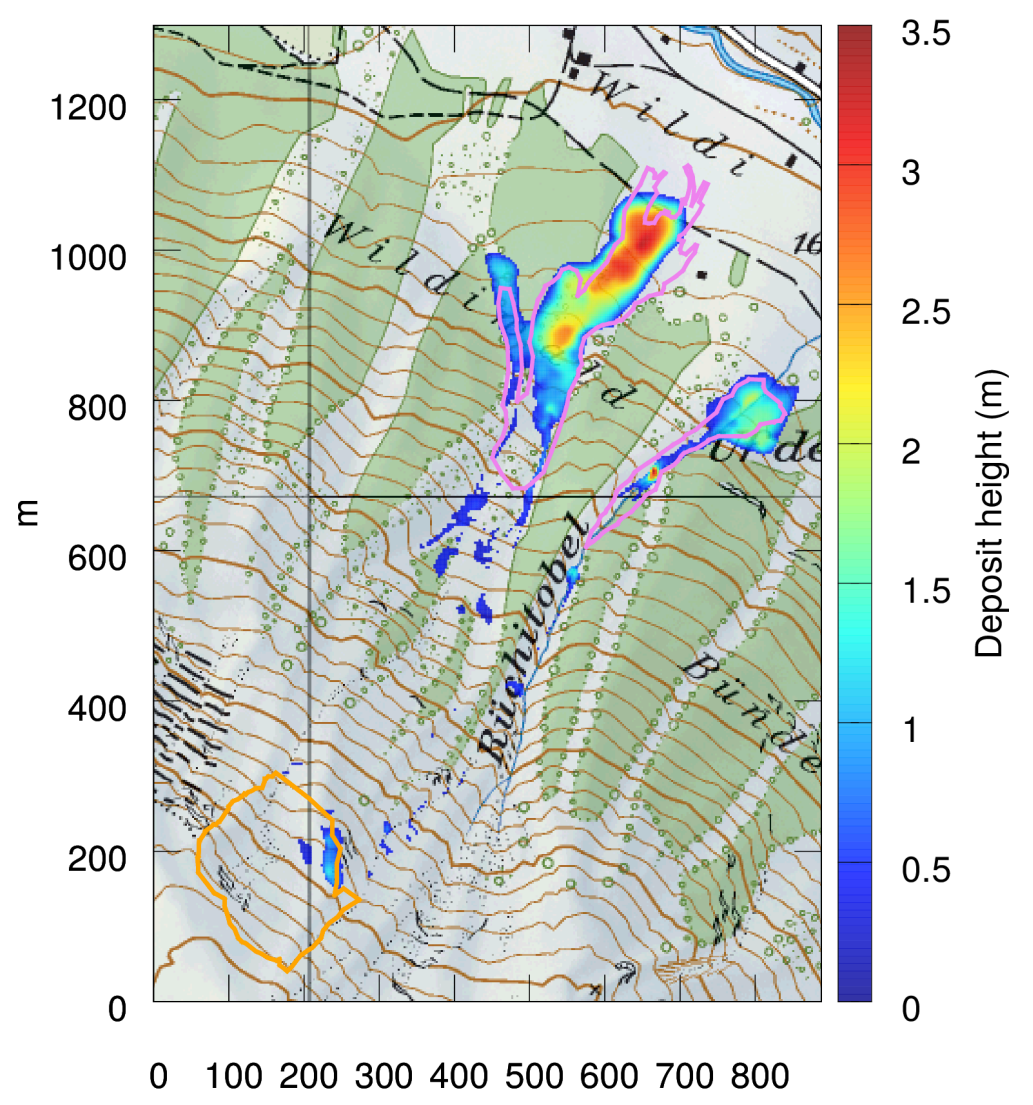

m

(a) Thermomechanical model RAMMS

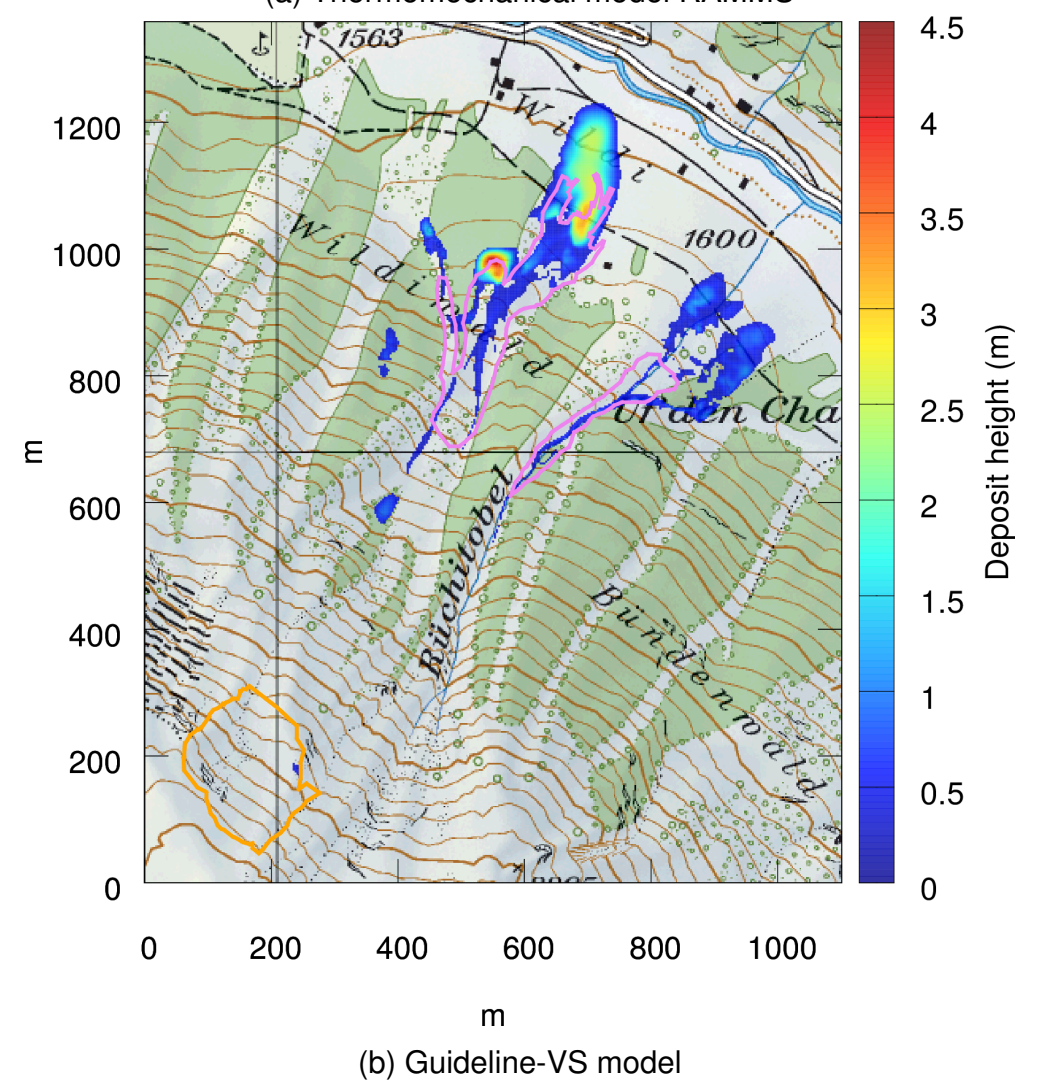

Figure S11: Wildi Davos 


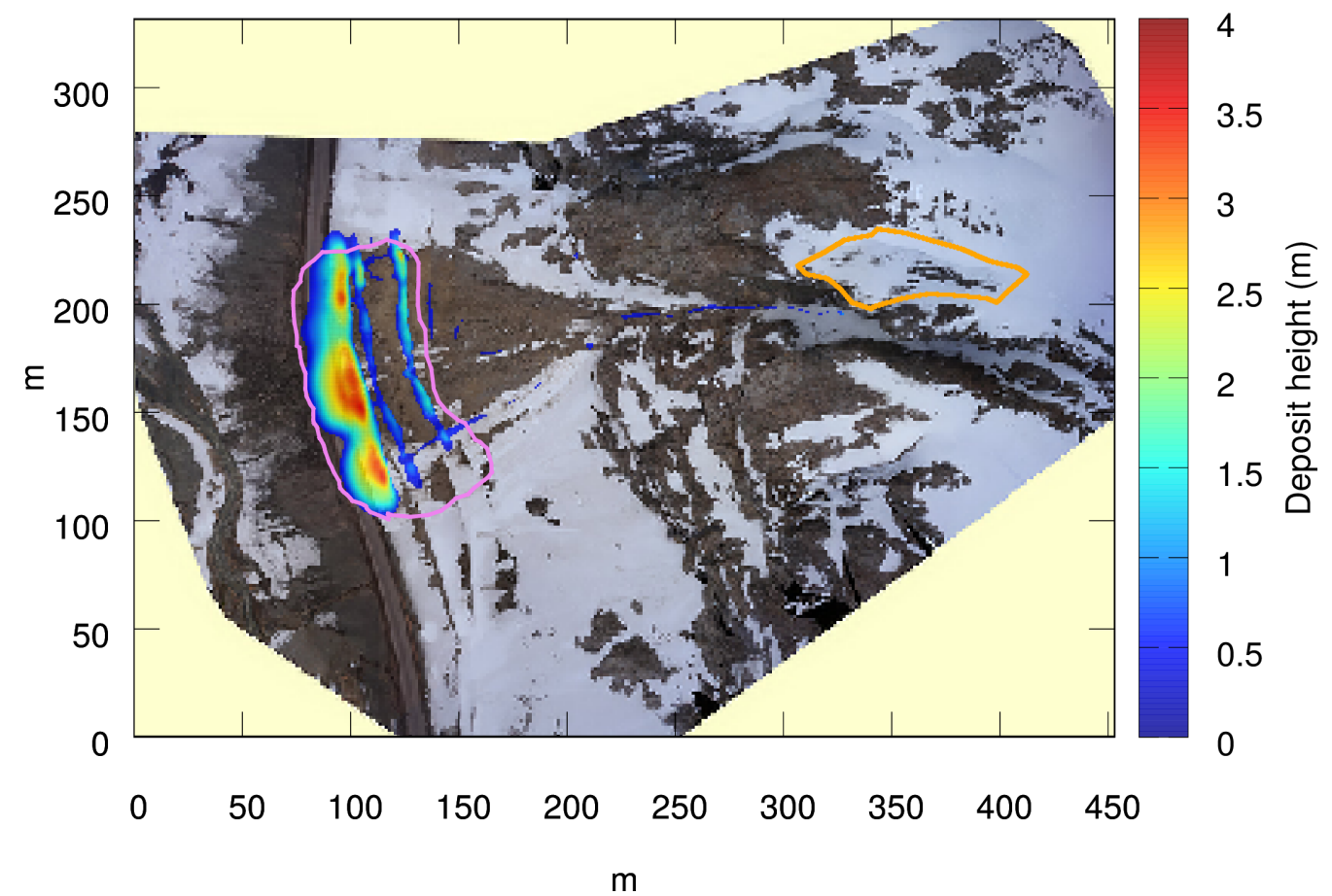

(a) Thermomechanical model RAMMS

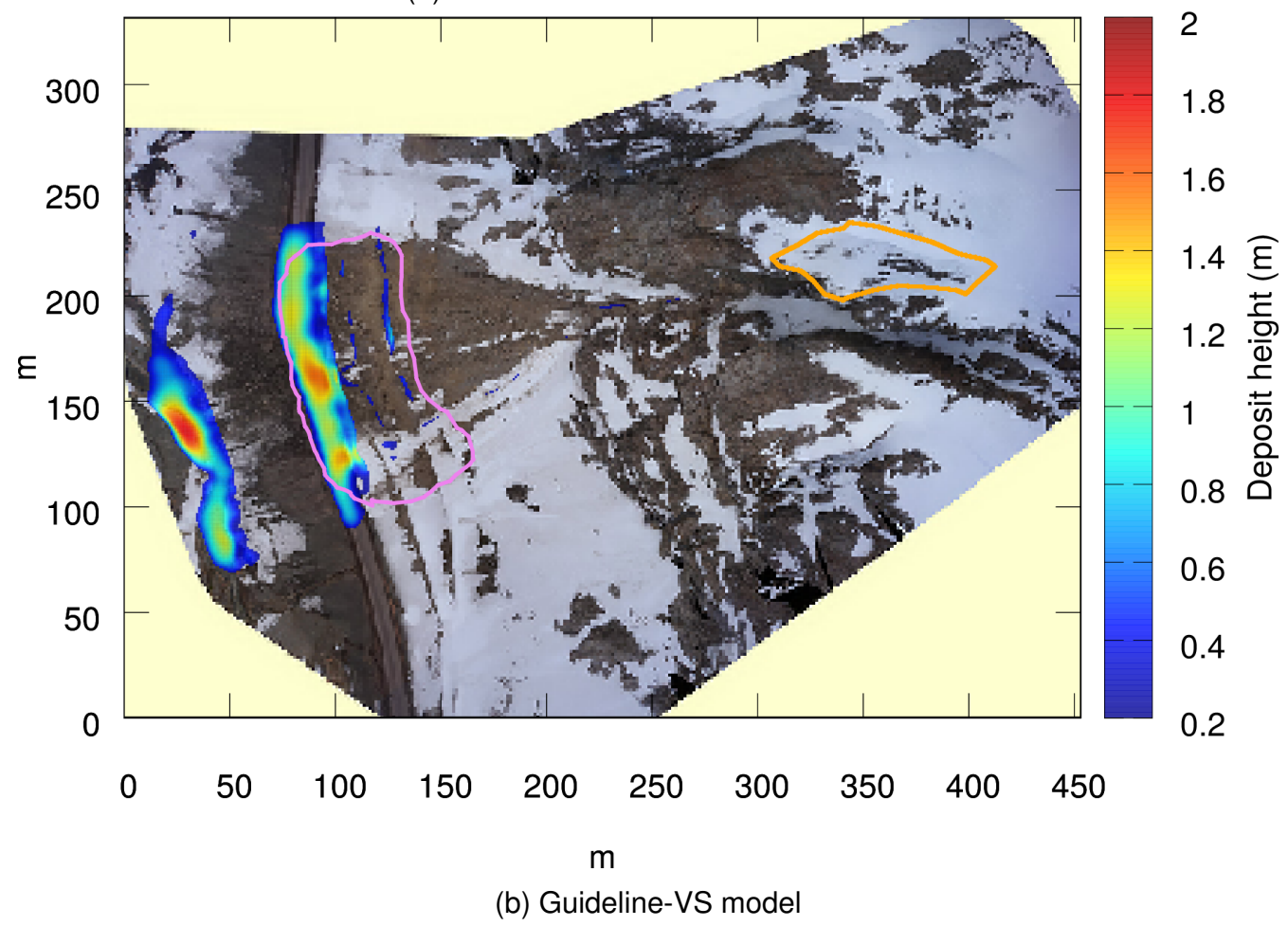

Figure S12: Codelco Andina CV-1 


\section{Supplement B}

The following pages show the runout sensitivity analysis calculations performed with the thermomechanical model RAMMS for the 12 case studies. The upper or left plot in each figure correspond to the 12 simulations performed interchanging all the initial and boundary conditions: fracture and erosion depth, density, snow temperature and liquid water content for the 12 case studies. The middle plot corresponds to simulations where the initial mass conditions were interchanged: fracture and erosion depth plus density are interchange among the 12 case studies. The lower or right plot corresponds to simulations where the initial snowcover conditions were interchanged: snowcover temperature and liquid water content for the 12 case studies. For each figure the measured released and deposits areas are shown in an orange and green polygon, respectively. 

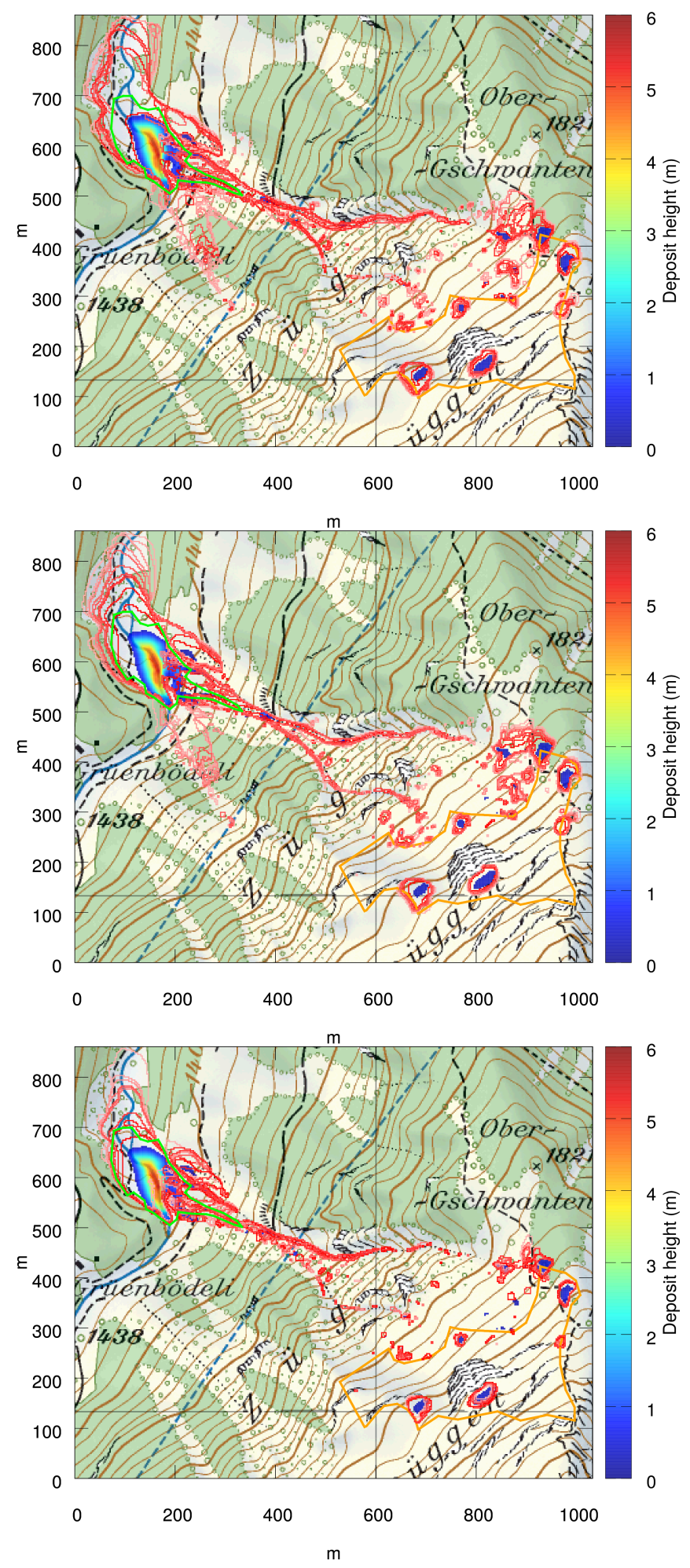

Figure S13: Gruenbodeli Davos 

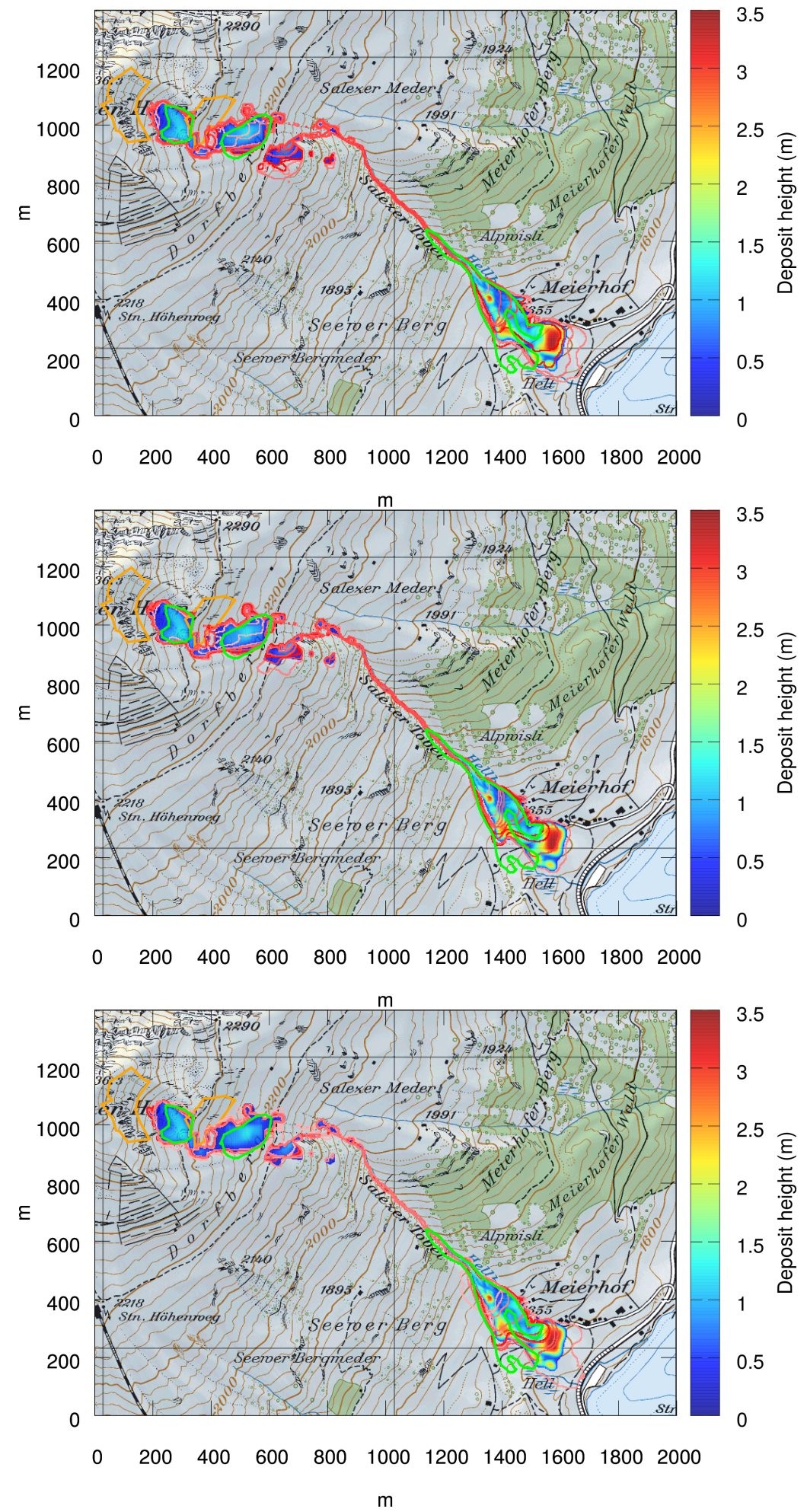

Figure S14: Salezer Davos 


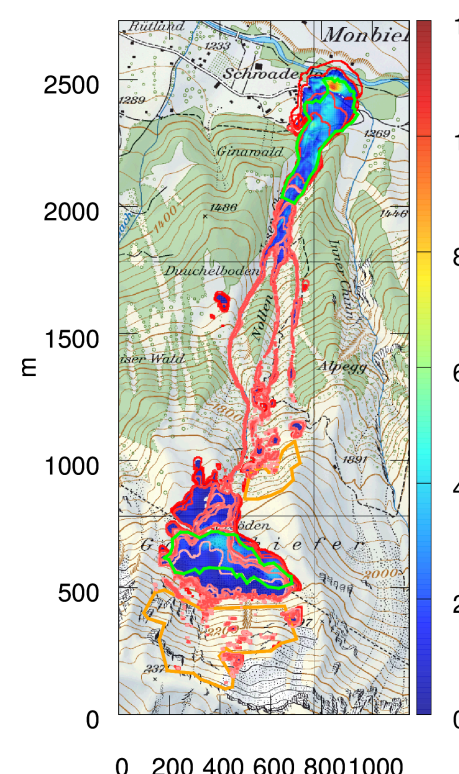

$\mathrm{m}$

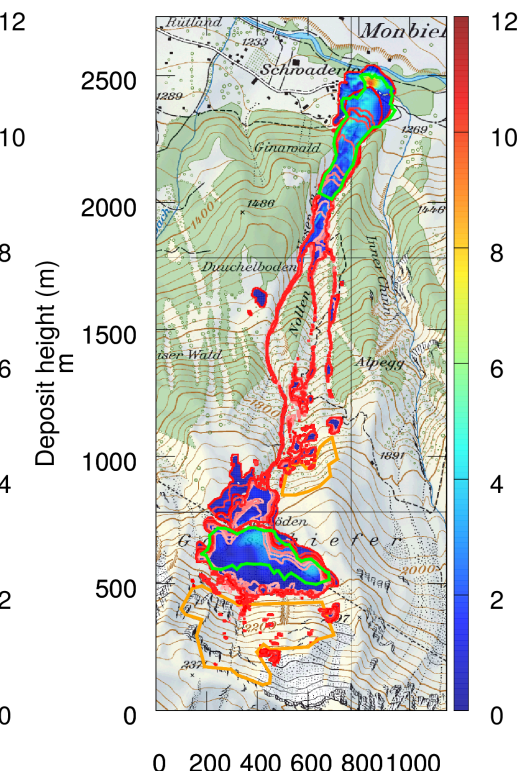

m

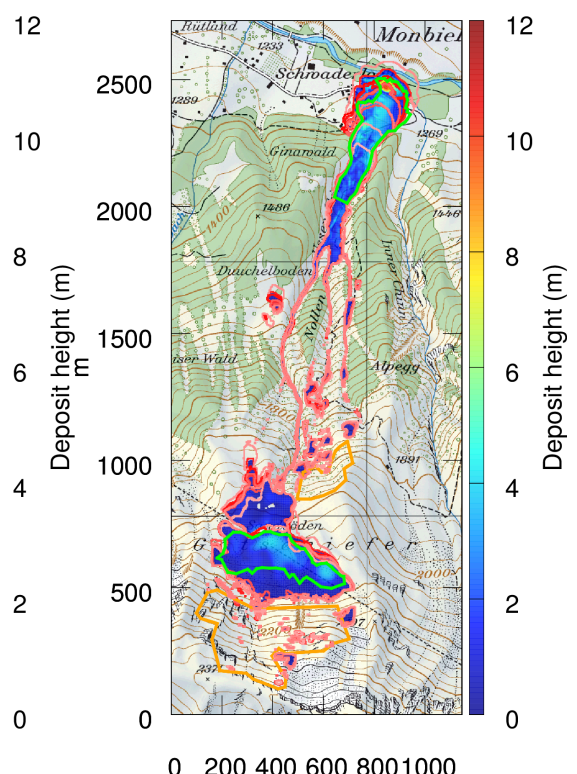

$\mathrm{m}$

Figure S15: Gatschiefer Davos 

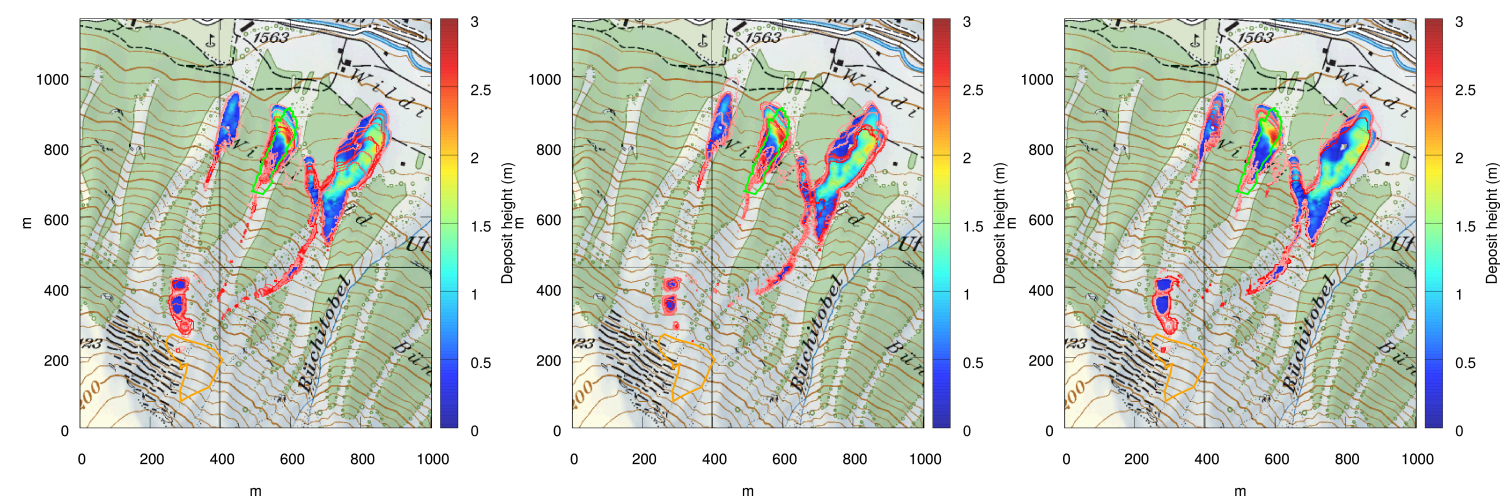

Figure S16: Braemabuhl 2013 Davos 

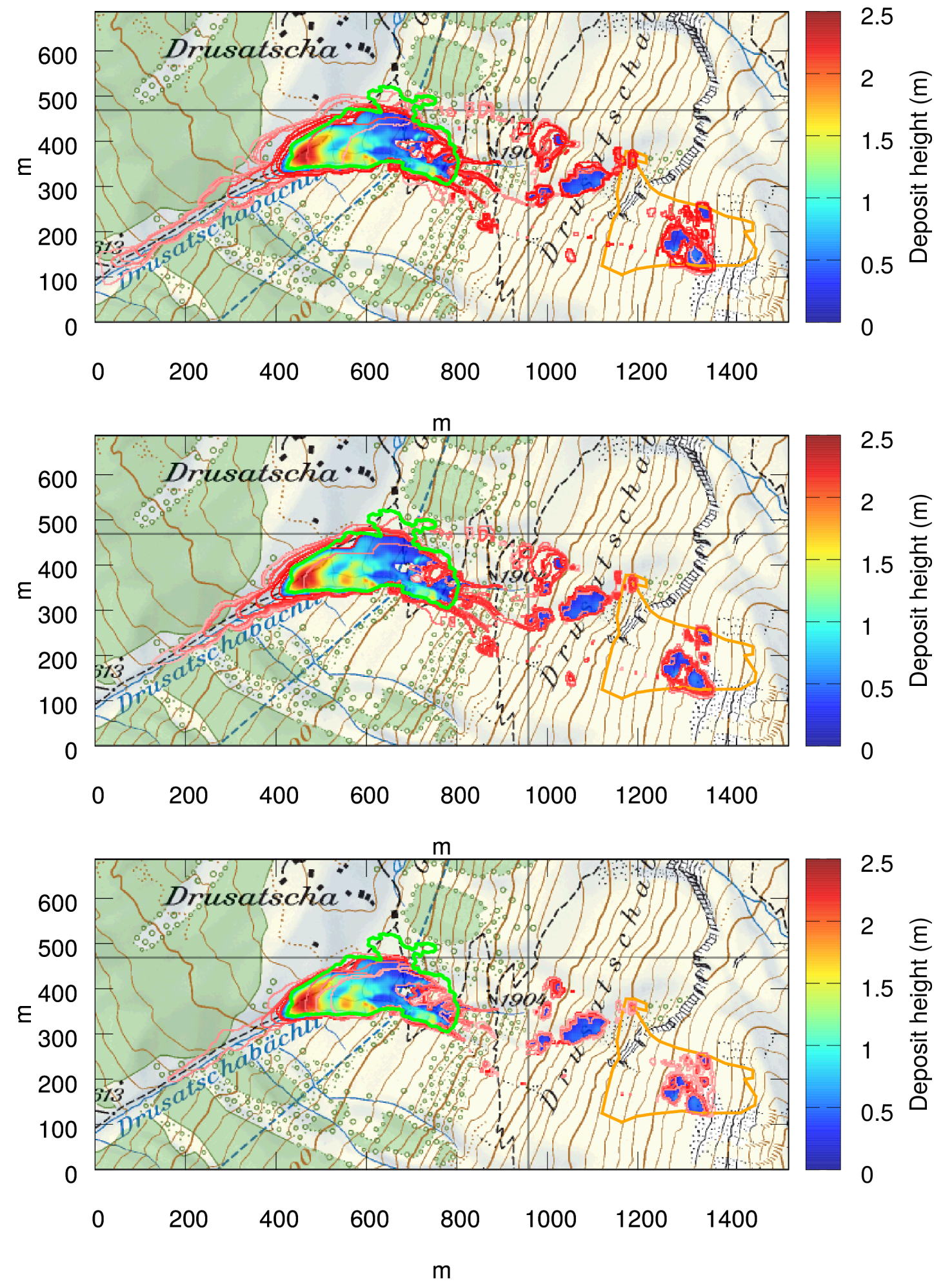

Figure S17: Drusatscha Davos 

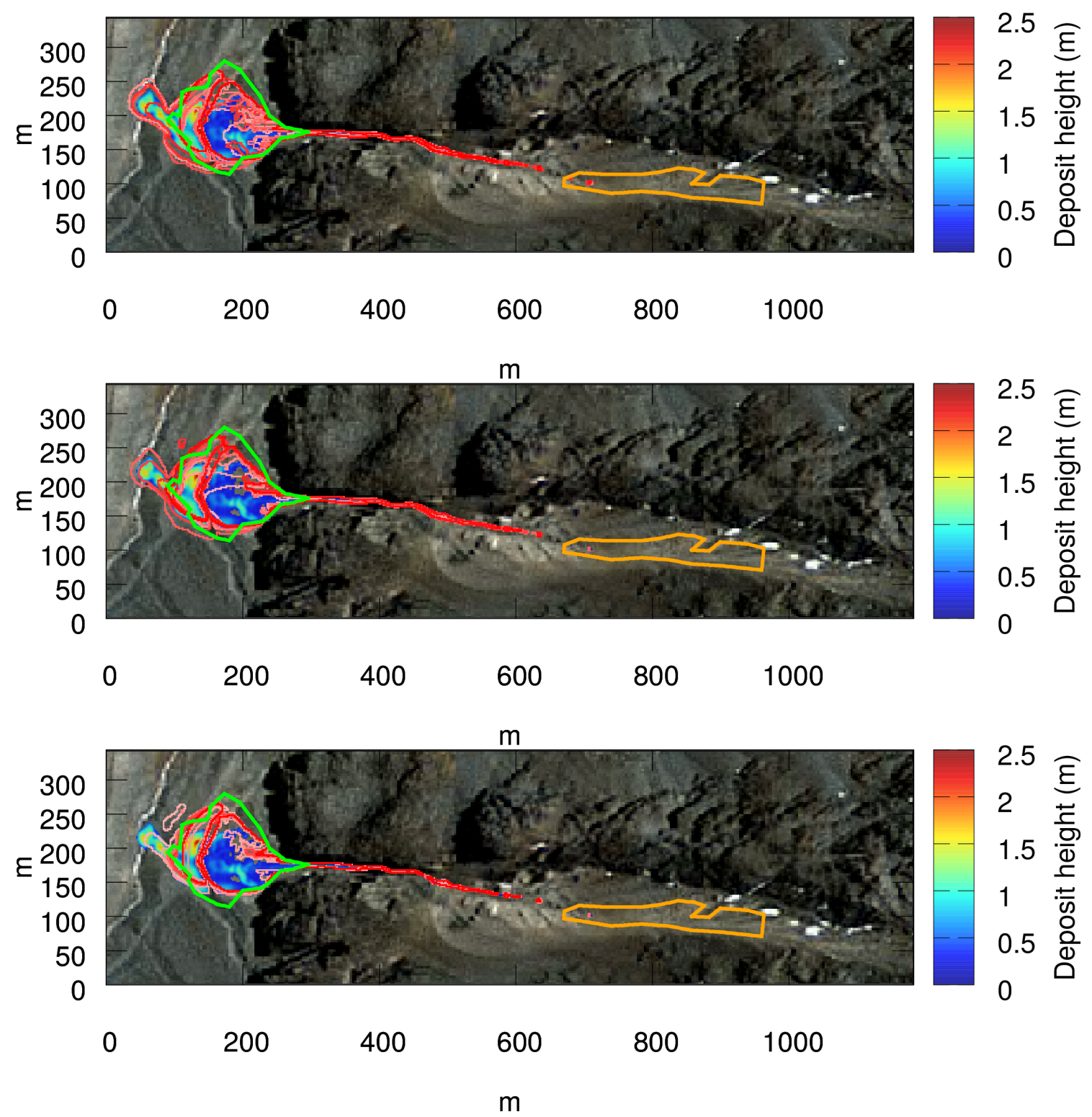

Figure S18: Codelco Andina Chile MO-4 

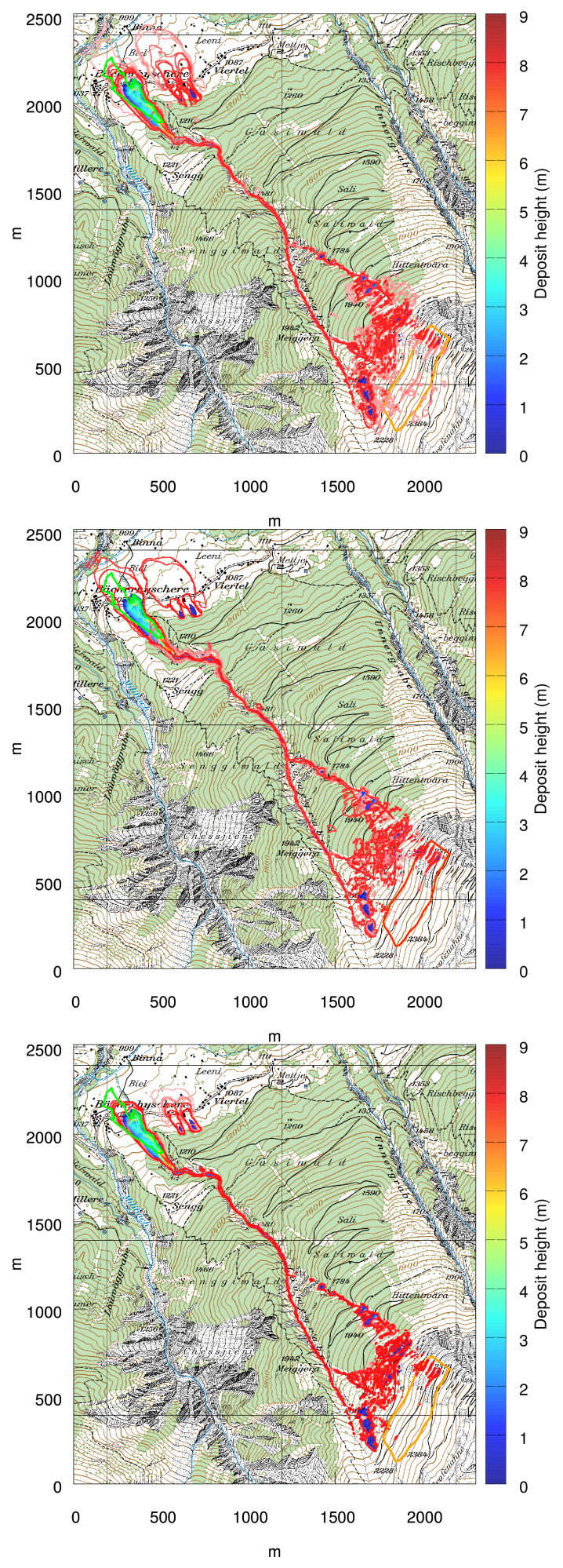

Figure S19: Grengiols 


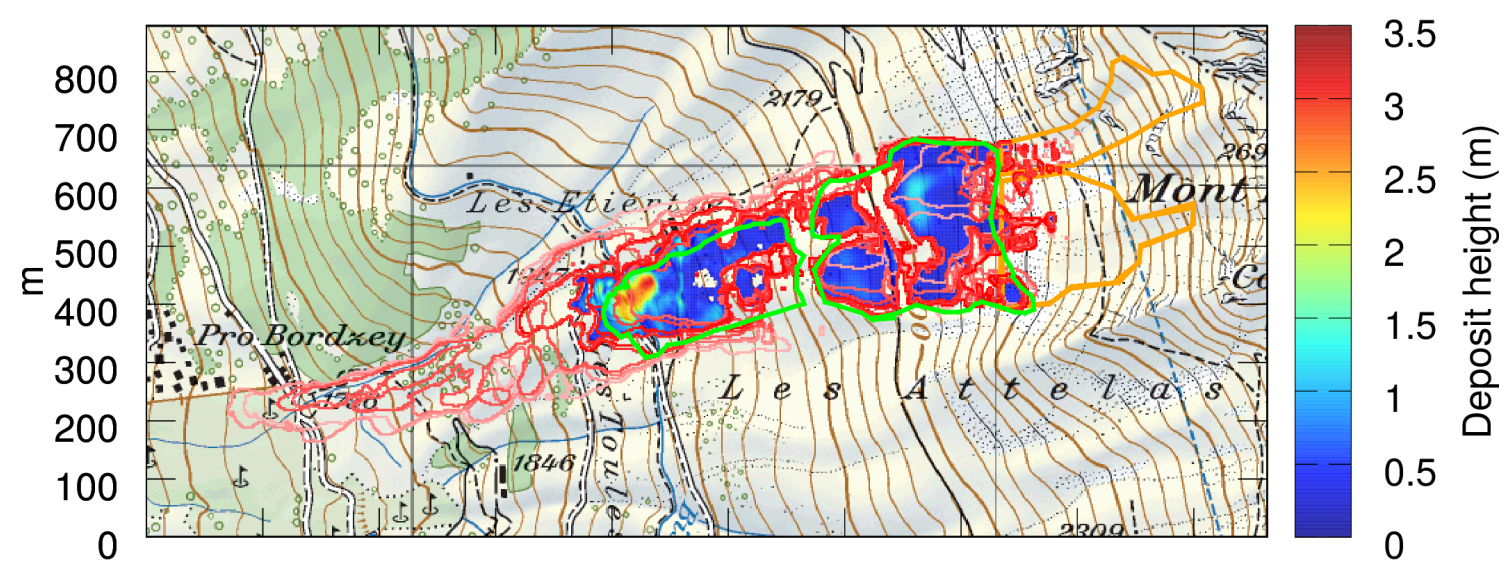

$\begin{array}{llllllllll}0 & 200 & 400 & 600 & 800 & 1000 & 1200 & 1400 & 1600 & 1800\end{array}$

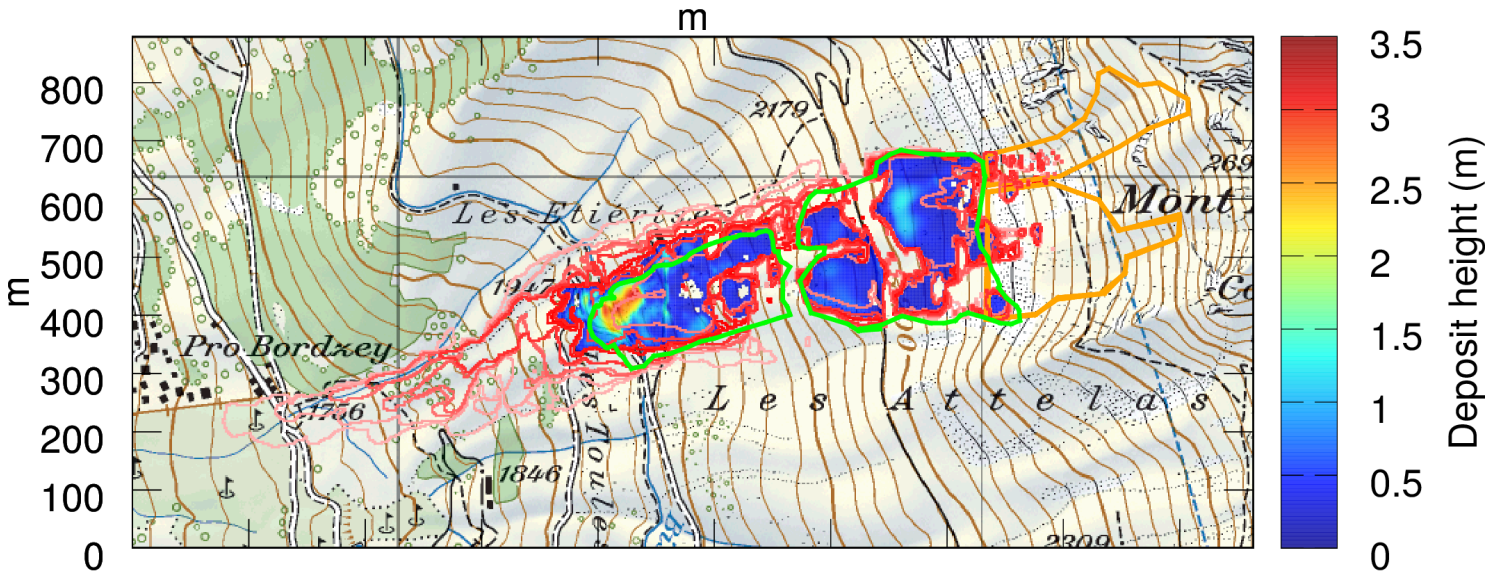

$\begin{array}{llllllllll}0 & 200 & 400 & 600 & 800 & 1000 & 1200 & 1400 & 1600 & 1800\end{array}$

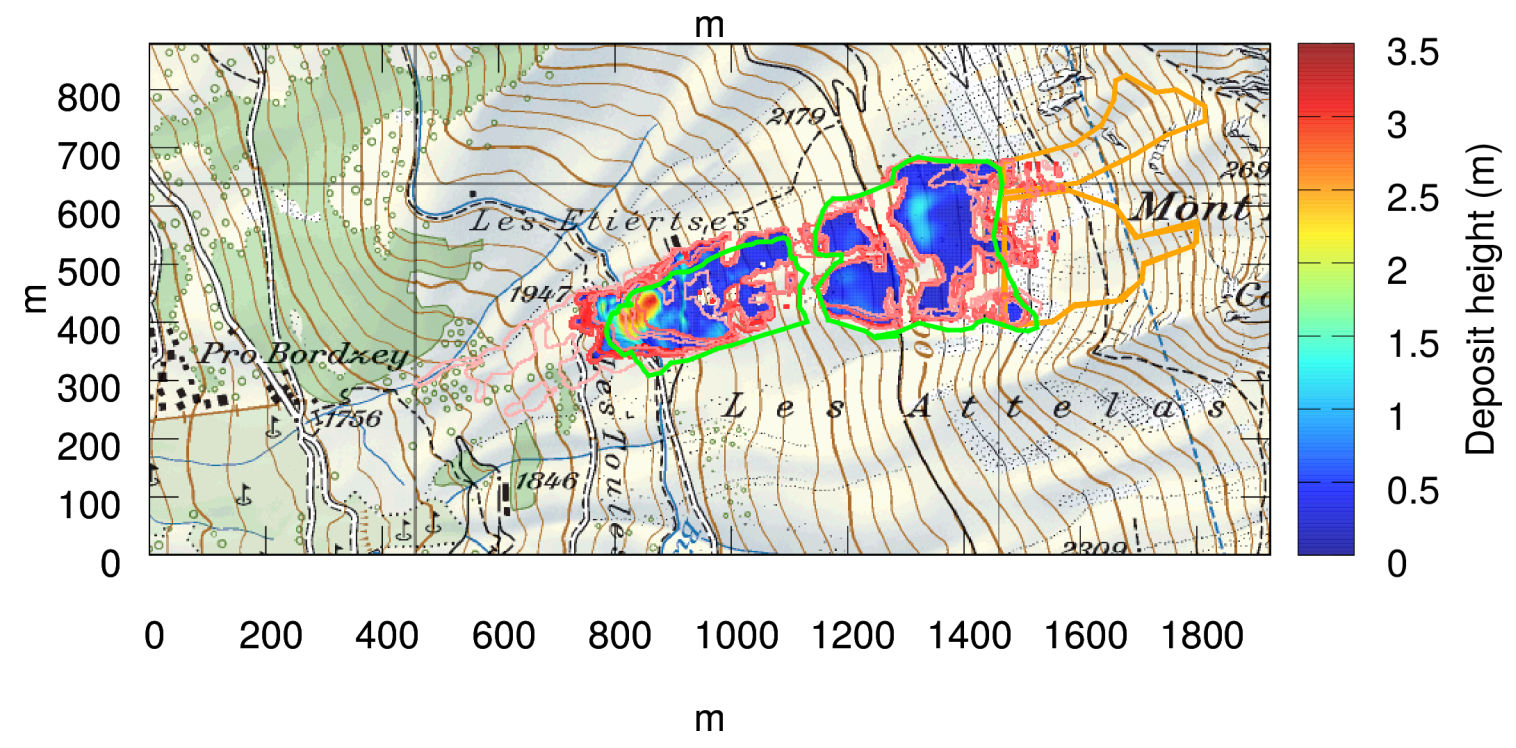

Figure S20: Mont Rogneux Verbier 

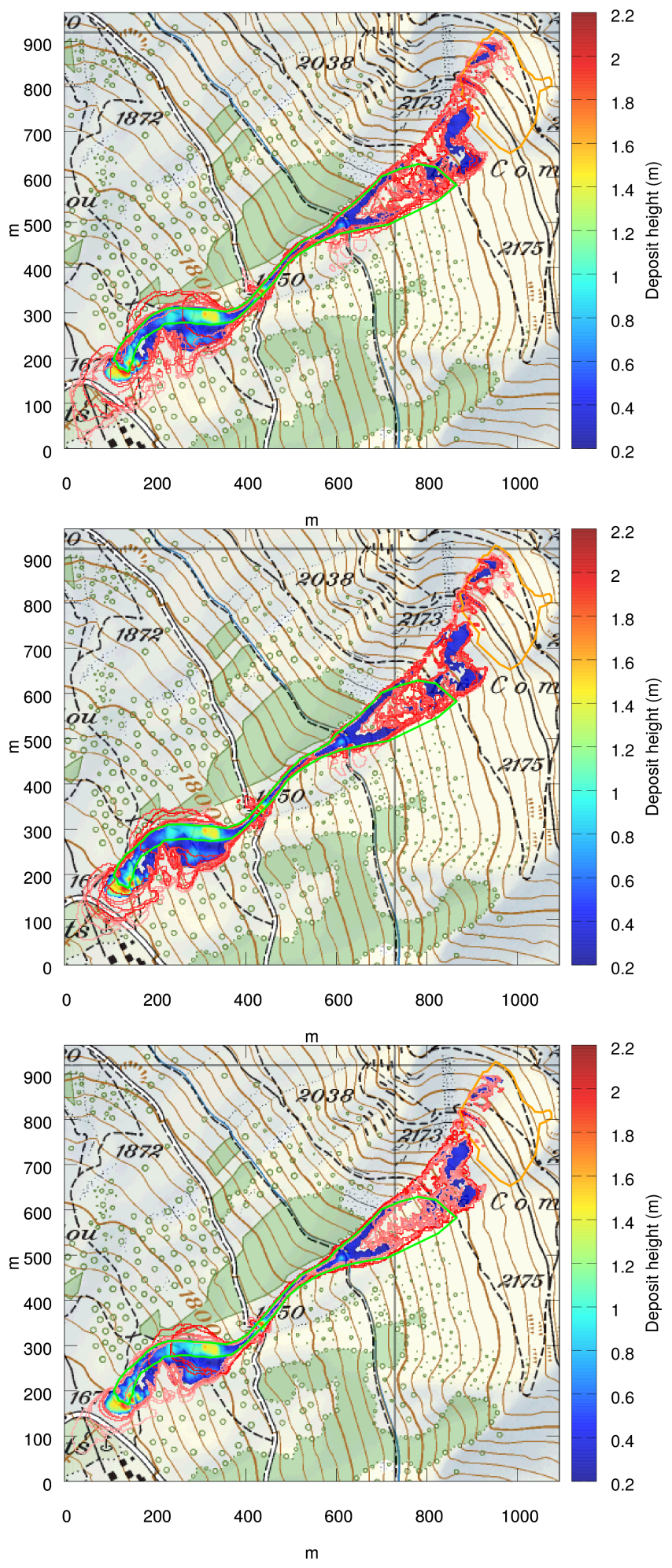

Figure S21: Ba Combe Verbier 

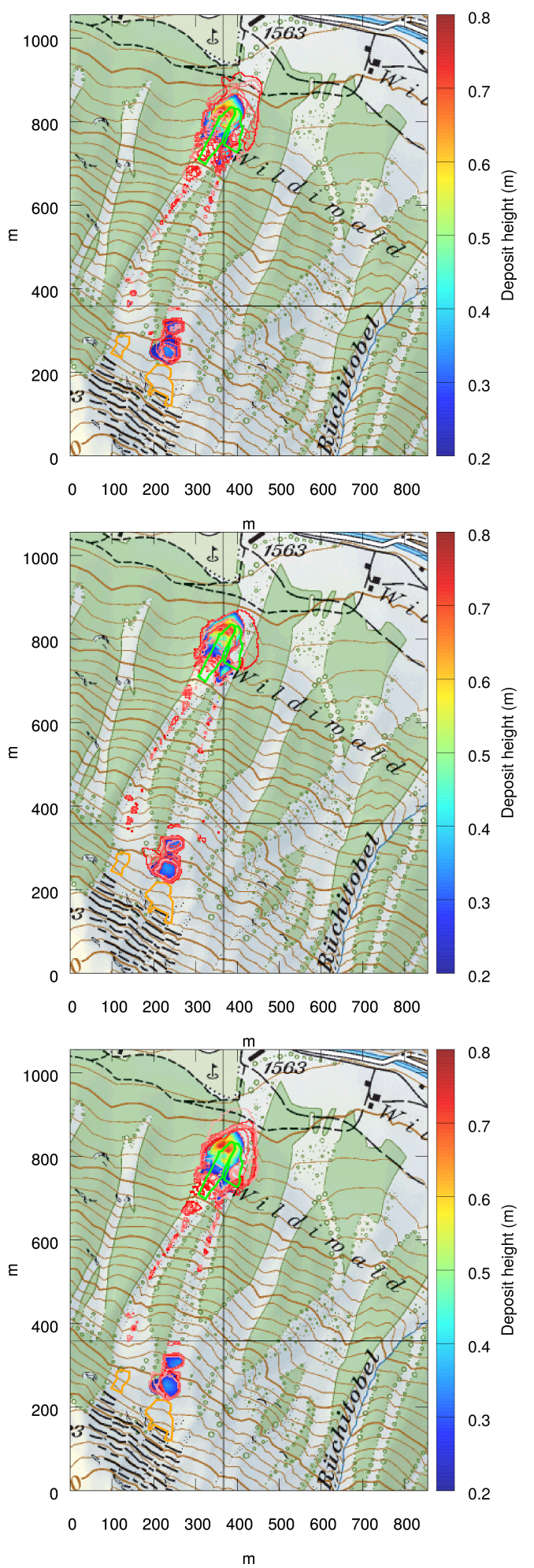

Figure S22: Braemabuhl Verbauung Davos 

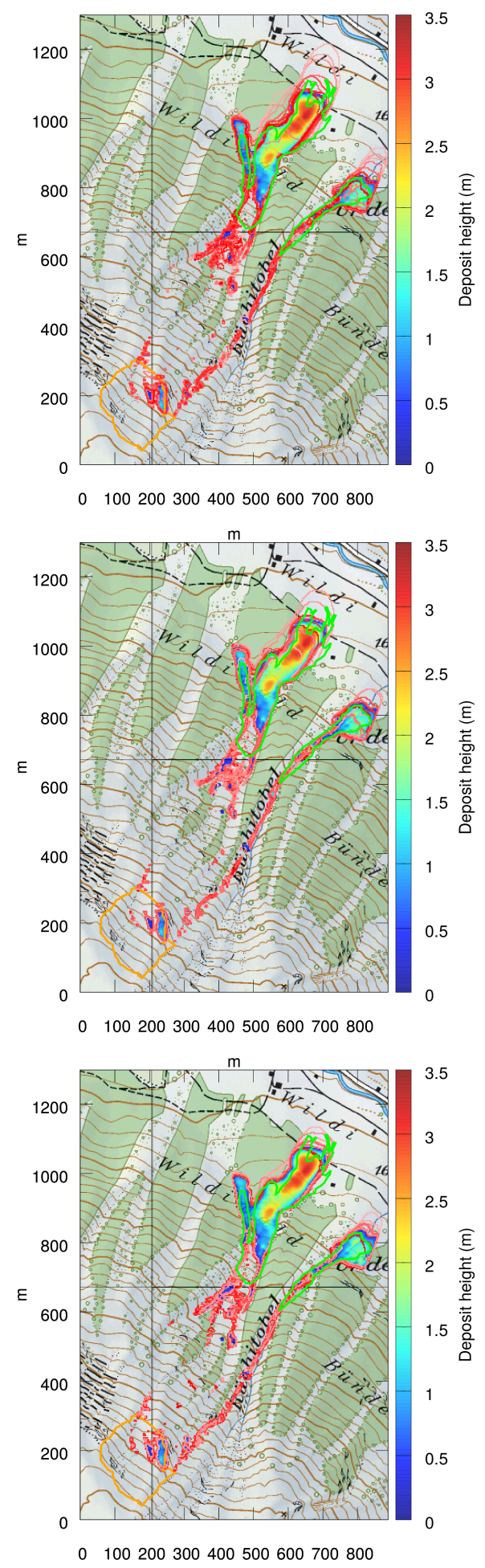

$\mathrm{m}$

Figure S23: Wildi Davos 

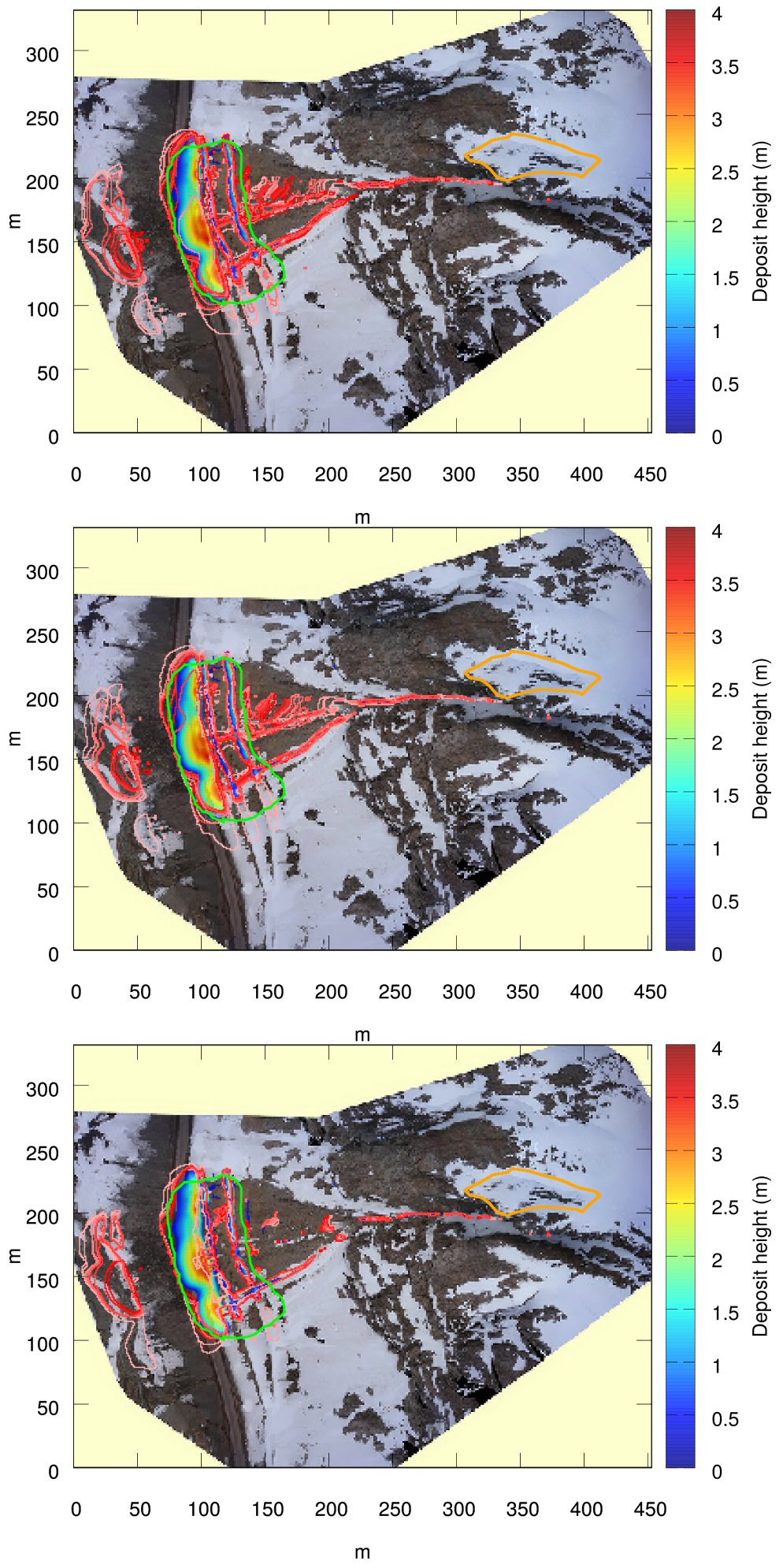

Figure S24: Codelco Andina Chile CV-1 